\title{
Enabling access to household refrigeration services through cost reductions from energy efficiency improvements
}

\author{
Won Young Park (D) - Nihar Shah • Amol Phadke
}

Received: 13 November 2017 / Accepted: 11 June 2019/Published online: 8 July 2019

(C) The Author(s) 2019

\begin{abstract}
Refrigerators are widely used by consumers with access to the electricity grid but rarely used in offgrid settings where households rely on a limited supply of electricity such as that by a stand-alone solar home system, because refrigerators' power consumption requires a solar system size that is unaffordable for most consumers. Reducing the power consumption of refrigerators by improving their efficiency is one solution to this issue. In this paper, we assess the technical potential and costs of using commercially available technology to reduce the energy consumption of small (50- and 100-L) refrigerators. Our analysis shows that refrigerator electricity consumption can be reduced by about $50 \%$ and $70 \%$ using commercially available energy-efficient components at an incremental cost of about $\$ 45-\$ 60$ and $\$ 100-\$ 120$ per unit, respectively. Further, we find that highly efficient small refrigerators can be potentially available less than $\$ 300$ if they sold at scale unlike much higher prices seen in the market today. We also find that the total annualized cost of an off-grid solar home system (including the cost of the refrigerator) can be decreased by about $50 \%$ if the most efficient refrigerator we analyzed is used, compared with the same energy system with a standard refrigerator because the additional cost of the efficient refrigerator is significantly lower than the cost savings due to smaller capacity requirements for panels and batteries. We recommend
\end{abstract}

W. Y. Park $(\bowtie) \cdot$ N. Shah $\cdot$ A. Phadke

Energy Analysis and Environmental Impacts Division, Lawrence Berkeley National Laboratory, Berkeley, CA, USA

e-mail: wypark@lbl.gov that policies such as awards, procurement, and standards be considered to facilitate the adoption of energyefficient refrigerators in off-grid and microgrid settings.

Keywords Refrigerators · Energy efficiency · Energy access · Off-grid market · transformation

\section{Introduction}

Globally, refrigerators are among the most commonly used appliances; in 2015, more than $70 \%$ of households with access to electricity owned refrigerators (Majumder 2015). Developed economies have saturated refrigerator markets with most households owning at least one refrigerator, but ownership of refrigerators in developing economies varies significantly with income (Global LEAP 2016).

An estimated of over 1 billion people worldwide lack access to electricity and an additional 1 billion people have unreliable electricity access (Casillas and Kammen 2010; IEA 2015; Phadke et al. 2015). In regions where no electricity grid connection is available, deployment of solar home systems (SHSs) can be a key short-term strategy to supply electricity. According to a market survey conducted between late 2014 and early 2015, refrigerators were among the top five high-demand appliances for off-grid households and small and medium enterprises (Global LEAP 2015). However, refrigerators are rarely used with SHSs. This is partly because refrigerators, unlike other appliances, typically need to operate $24 \mathrm{~h}$ per day to preserve fresh food within the recommended temperature range, and the typical power 
consumption of a refrigerator requires a much larger SHS than would otherwise be needed; these large SHSs are unaffordable for most off-grid consumers, including those earning under $\$ 2$ per day. Highly efficient direct current (DC)-powered refrigerators that require smaller SHSs are expensive niche products that are also unaffordable for most consumers.

We estimate that a commonly sold SHS, which supports two lights, a radio, and a mobile charger that consume about 12 watts (W) and an estimated of 50 watt-hours $(\mathrm{Wh})$ per day, requires a 17-watt-peak (Wp) panel and an 18-ampere-hours (Ah) battery and costs about $\$ 100$ in manufacturer selling price (or about $\$ 200$ in market price). ${ }^{1}$ Adding a 100-liter [L] refrigerator that is used by grid-connected households and consumes 600 $\mathrm{Wh} /$ day would require increased SHS capacity, leading to a total incremental cost of about $\$ 1000$; the solar panel and battery system account for about $85 \%$ of that increase (see Table 4 for the assumptions we used for the SHS design). The significant cost increase to power a small commercially available refrigerator would make this SHS unaffordable for most of the off-grid population. As a result, refrigerators are rarely used with SHSs.

In this paper, we assess the technical potential to reduce the energy consumption of small refrigerators using commercially available technology in order to determine whether refrigerators could be made more affordable for off-grid populations (both the cost of the refrigerator and the cost of an SHS capable of powering a refrigerator). We also discuss the potential to reduce the cost of refrigeration services in other electricity access settings (mini- or microgrids).

The remainder of this paper is organized as follows:

We assess the energy consumption and price of small refrigerators used in Europe, the USA, and off-grid settings, and use a bottom-up approach to estimate the potential and cost of refrigerator efficiency improvements based on estimates of both the improvements and the costs of key refrigerator components commercially available but not widely adopted. We then estimate the potential to reduce the cost of refrigeration service by improving refrigerator efficiency, comparing the reduction in electricity costs for a typical consumer with the incremental costs of efficiency improvements. We finally discuss the implications of our findings and make recommendations for future research.

\footnotetext{
${ }^{1}$ For example, one of IDCOL's 20-Watt-peak (Wp) SHS with a battery, a charge controller, and two lamps was about $\$ 190$ in market price in 2014 (IDCOL 2014).
}

\section{Status of refrigerators used in off-grid settings}

Small DC-powered refrigeration products have been developed for off-grid use, mainly for mobile (or leisure) and medical (e.g., for storing vaccines) applications. Historically, gas- or kerosene-fueled refrigerators with an absorption cooling cycle were used in off-grid applications. However, absorption cooling is typically inefficient and has significantly higher operating costs compared with the vapor compression cooling used in typical gridconnected refrigerators. Further, absorption cooling is not adequate for keeping temperature in the range required to safely store vaccines $\left(2\right.$ to $8^{\circ} \mathrm{C} / 35.6$ to $46.4^{\circ} \mathrm{F}$ ) (PATH and WHO 2013). Solar refrigerators with battery storage were introduced in 1980s, but battery technologies were not mature enough at that time to support sustainable operation. Solar refrigerators have also been used for storing vaccines. These refrigerators connect directly to a photovoltaic (PV) energy system and use the PV-generated energy to freeze water (or other phase-change material) that forms an "ice bank" to keep the refrigerator cold (PATH and WHO 2013; McCarney et al. 2013). ${ }^{2}$ This battery-free refrigeration technology has had limited success. This technology is sometimes used by households but rarely because these units are significantly more expensive (e.g., $>\$ 500-\$ 600$ for a 50 -L product) than similarly sized refrigerators used by grid-connected households (which cost approximately USD \$100-\$200) (PATH and WHO 2013; McCarney et al. 2013).

It is difficult to project how large the off-grid refrigerator market could be in the medium term (e.g., within 510 years) and to estimate potential cost reductions, given economies of scale. At the same time, the market growth will be accelerated by technological innovation and policy intervention. A manufacturer source roughly estimated sales to be 1.5 million units per year of which 1 million units for leisure or mobile products. ${ }^{3}$ Global LEAP (2016) projected that the off- and unreliable-grid refrigerator market has potential to grow from 9 million to 65 million units per year between 2015 and 2020 under the scenario of today's best-in-class products (e.g., a $45 \mathrm{~W} / 50$ $\mathrm{L}$ refrigerator at $\$ 300$ ) becoming widely available.

\footnotetext{
${ }^{2}$ The World Health Organization (WHO) provides a performance, quality, and safety specification for a refrigerator and water-pack freezer (compression cycle, solar direct drive without battery storage), as well as guidelines for manufacturers of solar power systems and vaccine refrigerators.

${ }^{3}$ The identity of the manufacturer source interviewed for this information has been kept confidential because they requested anonymity as a condition of speaking with authors.
} 
Vapor compression refrigerators in off-grid settings are typically DC-powered and consume less electricity than equivalently sized alternating current $(\mathrm{AC})$ refrigerators. ${ }^{4}$ However, off-grid vapor compression refrigerators appear much more expensive than AC-powered products (Garbesi et al. 2011). Commercially available 50- to 165-L DC refrigerators are estimated to consume about 40-73 kilowatt-hours (kWh)/year (110-200 Wh/ day) at ambient temperature $32^{\circ} \mathrm{C}\left(90{ }^{\circ} \mathrm{F}\right)$ (GIZ 2016, SunDanzer n.d.). An AC refrigerator of similar size typically consumes about twice as much electricity and costs about $\$ 100$ to $\$ 200$ while energy-efficient DC refrigerators do not appear to be available for less than \$500 (Global LEAP 2016; GIZ 2016; WHO 2016). These higher prices are likely because of higher mark ups, higher costs of efficient components (e.g., DC compressors), and a lack of economy of scale in producing these niche products. Thus, the data currently available on the cost of small efficient DC refrigerators likely do not accurately represent the cost of small efficient refrigerators deployed at scale. To evaluate whether energy-efficient refrigerators can reduce the cost of providing refrigeration service in off-grid settings, we need to know the cost of small efficient refrigerators produced at scale and cannot just base it on the current prices of efficient DC refrigerators. Hence we use a bottom-up approach to estimate the cost and price of small efficient refrigerators at scale that can be used in off-grid settings.

\section{Price and performance of small, commercially available energy-efficient refrigerators}

We assess the price and performance of some of the most efficient commercially available small refrigerators typically used in grid-connected settings (where the power source is AC). Given that $\mathrm{AC}$ refrigerators are not a niche product, this assessment provides insights into the cost reduction achievable from economies of scale for small, efficient, DC-powered refrigerators. We can also use these data to cross-check our bottom-up estimates of the price and performance of small efficient refrigerators.

We obtained the market data for this analysis from the US ENERGY STAR database and Topten, which provide information on the best-performing appliances

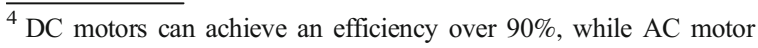
efficiency declines to less than $80 \%$ as the motor becomes smaller.
}

and equipment, including refrigerators, available in the USA, Europe, and China. Our initial screening analysis focused on small (45- to 150-L) products because only small refrigerators are likely to be affordable in off-grid settings (Global LEAP 2016).

Although the procedure for measuring refrigerator energy efficiency is broadly similar across countries, a number of factors can result in variation in energy consumption values (e.g., $\mathrm{kWh} /$ year) across countries, in particular, different specifications for ambient temperature and refrigerator compartment internal temperature in the test procedure. For example, the US standard is based on an ambient temperature of $32.2^{\circ} \mathrm{C}\left(90^{\circ} \mathrm{F}\right)$, but the EU standard is based on an ambient temperature of $25{ }^{\circ} \mathrm{C}$. The US standard uses a high ambient temperature instead of adding door openings and addition of warm contents. China recently revised its national standard GB12021.2, referring to the International Electrotechnical Commission (IEC) 62,252:2015 standards (parts 1, 2, and 3), effective October 2016, based on ambient temperatures of $16{ }^{\circ} \mathrm{C}$ and $32{ }^{\circ} \mathrm{C}$ (VHK and ARMINES 2016; APEC 2016). ${ }^{5}$ Since most of the off-grid population is in the warmer regions of the world, we estimate energy consumption based on an ambient temperature of $32{ }^{\circ} \mathrm{C}$ for this analysis. For small refrigerators with volume equal to or less than $100 \mathrm{~L}$, we use an adjustment factor of 1.8, to scale energy use from a test standard based on IEC 62252:2007 (where the test ambient temperature is 25 ${ }^{\circ} \mathrm{C}$ with no door openings or addition of warm contents) to the US standard (where the test ambient temperature is $\left.32{ }^{\circ} \mathrm{C}\right) .{ }^{6}$ As the actual field energy use in refrigerators will vary depending on parameters such as ambient conditions and number of times the refrigerator is opened and closed, we assess the sensitivity of our results to lower energy savings potential than those we assume in our analysis (see Appendix 4).

Figure 1 shows the reported annual energy use of 215 energy-efficient refrigerator models (with storage volume of 45 to $150 \mathrm{~L}$ ) in the USA, Europe, and China; we adjusted the reported performance of models in China

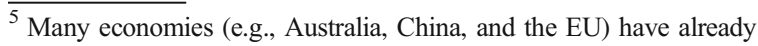
moved to, or are moving to, adopt the IEC 62552:2015 standard for household refrigerators, which was developed to harmonize international residential refrigeration testing and efficiency metrics.

${ }^{6}$ Based on a technical report by the APEC Energy Working Group (APEC 2016) and additional performance results of small refrigerators, those with a volume less than $100 \mathrm{~L}$ and refrigerator-freezers with a volume greater than $200 \mathrm{~L}$ have adjustment factors of 1.8 and $1.3-1.5$, respectively, to scale energy use from a test standard based on 25 to 32 ${ }^{\circ} \mathrm{C}$.
} 
Fig. 1 Annual energy use of energy-efficient refrigerators in China, Europe, and the USA. Notes: Data collected and adjusted by authors. The data include 180 US ENERGY STARqualified compact refrigerators (including models in a family or series) (U.S. EPA 2016), 18 EU $\mathrm{A}+++$ and $\mathrm{A}+$-rated single-door refrigerators (Topten.eu 2015), and 17 most efficient (Topten China-listed) refrigerators and refrigerator-freezers. "Volume" in this analysis refers to total storage volume or net volume

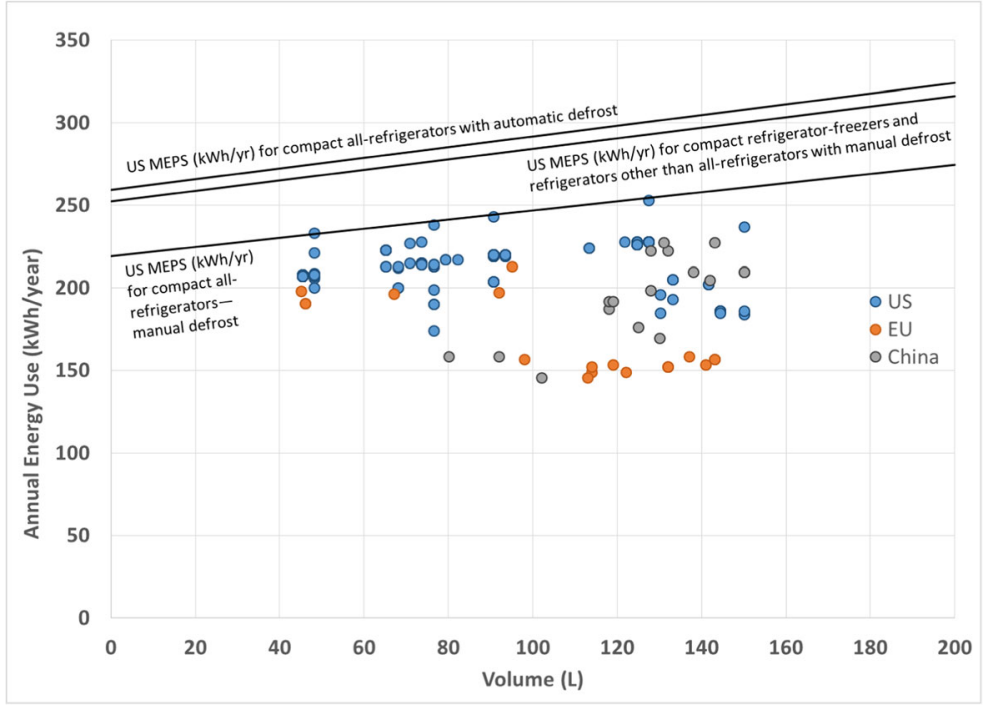

and Europe by a factor of 1.6-1.8 by volume to show their energy use based on the US standard with its ambient test temperature of $32{ }^{\circ} \mathrm{C}$. The energy consumption of US ENERGY STAR-qualified compact refrigerator models is $15-40 \%$ ( $24 \%$ on average) less than the relevant US MEPS. In other words, in the USA, the average consumption of typical compact refrigerators is likely slightly less than the MEPS, and the most efficient compact refrigerators are assessed to consume by up to $40 \%$ less electricity than is consumed by typical compact refrigerators.

According to the United States Department of Energy (U.S. DOE) (2011), more than $70 \%$ of compact refrigerators in the USA are in the retail price range of $\$ 75$ to $\$ 175$. Figure 2 shows market prices of 63 energyefficient models out of the 215 models in Fig. 1. Several energy-efficient models consume about $200 \mathrm{kWh} /$ year and are available for less than $\$ 150$. However, some models that consume about $170 \mathrm{kWh}$ or less appear to be much more expensive, likely due to the abovementioned reasons of cost of efficiency improvements or the lack of economy of scale. In the next section, we use a bottom-up approach to estimate the cost of efficiency improvements for refrigerators at scale.

\section{Bottom-up estimate of efficiency improvement potential}

We use a bottom-up approach to estimate the potential to reduce the energy consumption of small refrigerators and the corresponding costs. We use a methodology similar to that used in the US and European Union (EU) minimum energy performance standards (MEPS) rulemaking processes to estimate the incremental cost of efficiency improvements based on the incremental cost of key technology components that can be used in higherefficiency refrigerators. This approach typically identifies the additional potential of commercially available component technology that has not yet been realized or widely adopted.

This analysis focuses on vapor compression technology, which has been widely used for refrigerators or refrigerator-freezers around the globe. Our estimates of the efficiency improvement potential and associated incremental costs were taken mainly from technical studies (VHK and ARMINES 2016; U.S. DOE 2011) conducted for the European energy efficiency labeling program and the US appliance standards program. Both studies give detailed information on the cost and potential to improve efficiency using commercially available component technology. Tables 1 and 2 summarize characteristics of the baseline and energy efficiency improvement options that we assumed and analyzed.

\section{Baseline model}

Based on the findings from Figs. 1 and 2, we used one 50-L and one 100-L single-door baseline refrigerator 
Fig. 2 Purchase price of energyefficient refrigerators in China, Europe, and the USA. Source: Data collected by authors from on-line retailers. These data included 32 ENERGY STARqualified compact refrigerators (U.S. EPA 2016), 15 EU A+++ and A+-rated single-door refrigerators, and 16 most efficient (Topten China-listed) refrigerators and refrigeratorfreezers. Out of the 63 energyefficient models, 51 can be purchased for less than $\$ 200$

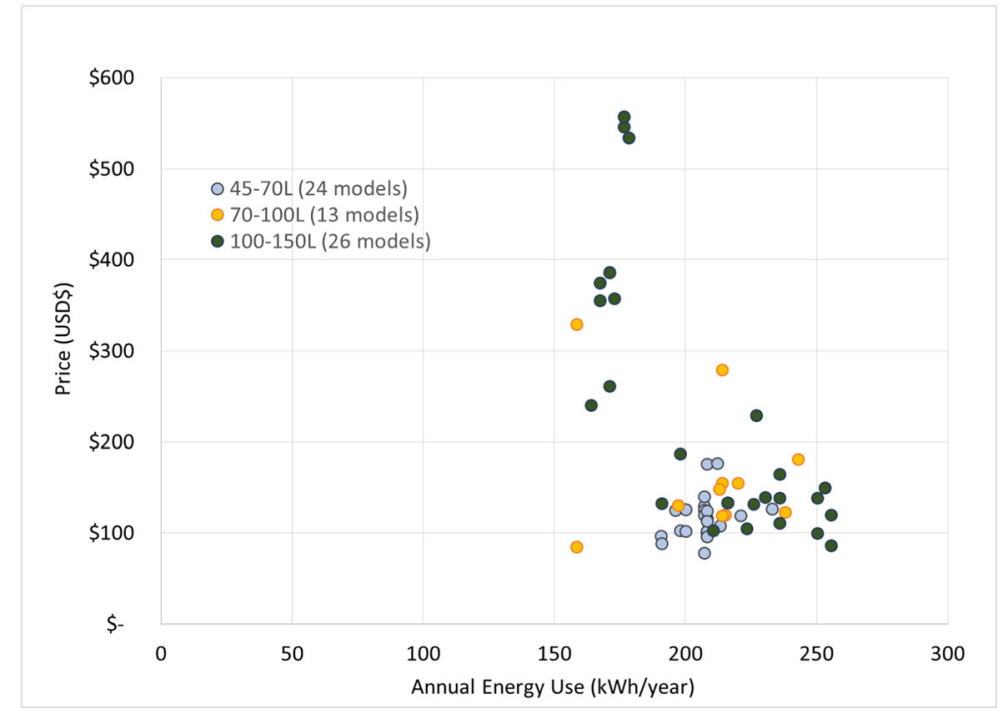

model to estimate cost-efficiency relationships for offgrid use. The baseline model operates on an AC singlespeed compressor. The $50-\mathrm{L}$ model is assumed to consume $207 \mathrm{kWh} /$ year, and the 100-L model $216 \mathrm{kWh} /$ year, based on consumption at $32{ }^{\circ} \mathrm{C} .{ }^{7}$ Those consumption values are $11-13 \%$ less than the US MEPS for compact refrigerators with manual defrost. Note that the baseline model does not represent the typical performance of small refrigerators in off-grid settings. It simply establishes a baseline against which the cost of improving efficiency is measured. (See Appendix 1 for details of the criteria for determining our baseline models.) We discuss several energy efficiency improvement options considered in this analyses next.

Increasing insulation thickness

Increasing insulation reduces energy consumption. Many small refrigerators have insulation (polyurethane cyclopentane foam) that is 2.54 to $3.81 \mathrm{~cm}$ (equivalent to 1 to 1.5 inches) thick while some energy-efficient offgrid refrigerators have thicker insulation (Global LEAP 2016; GIZ 2016; SunDanzer n.d.). As insulation thickness increases, interior volume decreases, or exterior cabinet dimensions increase, or a combination of both. This affects both incremental cost and consumer utility

\footnotetext{
$\overline{7}$ Although most climates have some seasonal variation throughout the year, we assume the energy consumption in refrigerators at $32{ }^{\circ} \mathrm{C}$, to isolate the impact of energy-efficient refrigerators on the design and cost of SHS.
}

(U.S. DOE 2011). It would be unrealistic to assume an unlimited increase in wall thickness. We assume that insulation can be increased up to $10 \mathrm{~cm}$ based on practical limits estimated by previous studies (VHK and ARMINES 2016; U.S. DOE 2011). We adjust the volume estimates to calculate the cost of increasing insulation thickness by $2 \mathrm{~cm}$ and $6 \mathrm{~cm}$ and the corresponding reduction in energy consumption. We assume that increasing insulation can reduce energy consumption significantly, up to about $40 \%$ at an incremental cost (i.e., manufacturer selling price) of $\$ 45$, based on the findings from VHK and ARMINES (2016) and U.S. DOE (2011). (See Appendix 2 for details about our assumptions on incremental cost and efficiency improvement potential.)

Vacuum insulation panels

Vacuum insulation panels (VIPs) provide thermal insulation and have better (lower) thermal conductivity ${ }^{8}$ than standard insulation, although it has some manufacturing complexities around corners where foam is required around the joins in the panels. The panels generally consist of a core material in an airtight envelope. They cannot cover a complete door panel because of structural design requirements (VHK and ARMINES 2016; U.S. DOE 2011). Typically, 2-cm-thick VIPs are used to replace standard insulation. Because the baseline

\footnotetext{
$\left.\overline{{ }^{8} 0.0035 \mathrm{~W} /(\mathrm{m} \mathrm{K}} \mid\right)$ for VIPs and $0.02 \mathrm{~W} /(\mathrm{m} \mathrm{K})$ for standard insulation (VHK and ARMINES 2016).
} 
Table 1 Characteristics of off-grid baseline refrigerator models

\begin{tabular}{|c|c|c|c|}
\hline & & $50 \mathrm{~L}$ & $100 \mathrm{~L}$ \\
\hline \multicolumn{2}{|l|}{ Refrigerated volume (L) } & 50 & 100 \\
\hline \multicolumn{2}{|l|}{ Width (centimeters $[\mathrm{cm}]$ ) } & 48 & 48 \\
\hline \multicolumn{2}{|l|}{ Depth (cm) } & 48 & 48 \\
\hline \multicolumn{2}{|c|}{ Height $(\mathrm{cm})$} & 55 & 85 \\
\hline \multicolumn{2}{|c|}{ Refrigerator envelope surface (square meters $\left[\mathrm{m}^{2}\right]$ ) } & 1.11 & 1.64 \\
\hline \multicolumn{2}{|l|}{ Average wall thickness (cm) } & 38 & 38 \\
\hline \multicolumn{2}{|c|}{ Compressor coefficient of performance (COP) (W/W) } & 1.4 & 1.4 \\
\hline \multicolumn{2}{|l|}{ Cooling power (W) } & 63 & 93 \\
\hline \multirow[t]{3}{*}{ Annual electricity consumption ( $\mathrm{kWh} /$ year) } & Per refrigerated volume (based on the EU test standard) & 2.3 & 1.2 \\
\hline & Based on the EU test standard (ambient temperature $25^{\circ} \mathrm{C}$ ) & 115 & 120 \\
\hline & Based on the US test standard (ambient temperature $32^{\circ} \mathrm{C}$ ) & 207 & 216 \\
\hline
\end{tabular}

See Appendix 1 for details

compact refrigerator models defined in U.S. DOE (2011) have similar sizes and specifications to our baseline models, we assume that adding VIPs in sizes similar to the options applied in U.S. DOE (2011) can reduce energy consumption by $10-20 \%$ at an incremental cost of \$24-\$36. (See Appendix 2 for more detail on our assumptions on incremental cost and efficiency improvement potential.)

\section{Efficient compressors}

The role of vapor compression in a refrigeration system is to take in a low-pressure refrigerant vapor and compress it into a high-pressure vapor. Compressor efficiency is affected by several factors, including pump design and motor efficiency. Possible ways to improve compressor efficiency include changing the compressor type, tightening production tolerances, using lighter materials, or oversizing the compressor (especially for low-capacity single-speed compressors). In the US market, commercially available single-speed compressors used in small refrigerators (capacity less than $60 \mathrm{~W},<200$ British thermal units $[\mathrm{Btu}] / \mathrm{h}$ ) were estimated to have a coefficient of performance (COP) of 1.0 or less, which is significantly less efficient than typical compressors used on larger refrigerators (U.S. DOE 2011). However, in Europe in 2015, similar size compressors (R600a iso-butane) with COP of 1.4 or above were available (VHK and ARMINES 2016). According to VHK and ARMINES (2016), compressors with a COP of 1.7 are available for all sizes of refrigerators (in terms of cooling capacity), and the estimated incremental costs for efficient compressors are $\$ 4-\$ 5$ for 0.1 improvement in nominal COP

Table 2 Energy efficiency improvement options for small refrigerators

\begin{tabular}{|c|c|c|c|c|}
\hline \multirow[t]{2}{*}{ Energy efficiency improvement option } & \multicolumn{2}{|c|}{$\%$ energy savings } & \multicolumn{2}{|c|}{ Incremental manufacturing cost (USD) } \\
\hline & $50 \mathrm{~L}$ & $100 \mathrm{~L}$ & $50 \mathrm{~L}$ & $100 \mathrm{~L}$ \\
\hline Increasing insulation thickness $(+2 \mathrm{~cm})$ & 18 & 25 & 10 & 15 \\
\hline Increasing insulation thickness $(+6 \mathrm{~cm})$ & 34 & 40 & 30 & 45 \\
\hline Use of a higher-efficiency compressor (COP $1.4 \rightarrow 1.7$ ) & 20 & 20 & 15 & 15 \\
\hline Use of a DC variable-speed drive compressor & 23 & 23 & 27 & 27 \\
\hline Use of vacuum insulation panels & 10 & 20 & 24 & 36 \\
\hline
\end{tabular}

It is important to note that the percent energy savings numbers are not additive, but multiplicative in nature

Incremental manufacturing cost in this study refers to manufacturer selling price

Source: Authors' estimates based on VHK and ARMINES (2016) (EU preparatory/review study), Shah et al. (2014a, b), and U.S. DOE (2011). (See Appendix 2 for details) 
(W/W). We assume that the compressor efficiency improvement (COP 1.4 to $1.7 \mathrm{~W} / \mathrm{W}$ ) can reduce refrigerator energy consumption by $20 \%$ at an incremental cost of $\$ 15$. (See Appendix 2 for details on our assumptions about incremental cost and efficiency improvement potential.)

\section{Variable-speed drives}

Compared with single-speed (on/off) compressors, variable-speed drive (VSD) compressors can operate at part load (and hence at higher efficiency) and reduce start-up energy losses and possible temperature overshoot by operating continuously rather than turning on and off as a fixed-speed compressor does. These features mean that VSD compressors use significantly less electricity than single-speed models (VHK and ARMINES 2016, Mallampalli and Bohori 2012). U.S. DOE (2011) found that, at lower capacity and smaller load, VSD compressors are far more efficient than single-speed compressors. VSD compressors typically use a permanent-magnet DC motor instead of the induction motor used in a single-speed AC compressor. DC motors in VSD compressors require more electronics than AC motors require. Highly efficient permanentmagnet motors have, at times, been cheaper than or cost competitive with conventional AC induction motors, in part because of the high cost of the copper and steel needed for AC induction motors (Shah et al. 2014a, b, Desroches and Garbesi 2011). However, the cost of copper has come down since 2011, making AC motors more attractive (InvestmentMine 2016). Thus, it is difficult to precisely estimate the current (and potential future) cost difference between DC motors and AC motors. However, the controls for a brushless DC (BLDC) motor require additional electronics costing an additional \$10-\$20 (Shah et al. 2014a, b). Here, we assume that a VSD compressor with BLDC motor improves efficiency, compared with an equivalent efficient $\mathrm{AC}$ compressor, by an average of $23 \%$ at an average incremental cost of \$27. Based on VHK and ARMINES (2016), Shah et al. (2014a, b), and U.S. DOE (2011), efficiency improvements range from 10 to $35 \%$, and incremental costs range from $\$ 10$ to $\$ 44$. (See Appendix 2 for details about our assumptions on incremental cost and efficiency improvement potential.)

Other possible efficiency improvement options include using phase-change material (PCM), optimizing thermostatic control including use of electric controls, and optimizing condenser and evaporator characteristics (e.g., fan, surface area) (VHK and ARMINES 2016; U.S. EPA 2014; Shah et al. 2014a, b; U.S. DOE 2011). For example, the EU preparatory/review study (VHK and ARMINES 2016) assessed a PCM that helps to stabilize refrigerator temperature, resulting in a roughly $5 \%$ efficiency gain for most base cases, and the addition of a fan to increase the air speed over the heat exchangers, resulting in an estimated efficiency gain of 3-4\%. PCMs are useful only for compartments with a stable operating temperature and can reduce flexibility of operation, while the efficiency gain is relatively small if VSDs are used. In this analysis, we focus on efficiency improvement options that are widely accepted rather than on the entire universe of possible efficiency options; therefore, we did not look at PCMs or that addition of a fan.

For smaller DC refrigerators, horizontal doors (topopening) may be preferred by manufacturers over vertical doors (side-opening). Measured with a standard test, energy consumption does not appear to differ significantly between AC-powered commercial refrigerators with horizontal doors and with vertical doors (U.S. DOE 2013). However, this appears to be an artifact of the standard test procedure not including door opening as part of the test rather than being an inherent characteristic of the products. Load processing with door openings and addition of warm contents is estimated to contribute an additional energy consumption about 6$20 \%$ to average electricity consumption (APEC 2016; Terrell 2006). Even though horizontal door refrigerators have an advantage over vertical door products in regard to saving energy that is lost when doors are opened, this advantage is not likely to be significant at homes, while the potential impact might be larger at small retail contexts where the door may be opened more frequently. In this analysis, we account only for electricity consumption estimated under a standard test with a high ambient temperature. We do not evaluate the difference in energy consumption by door types or number of door openings.

\section{Results}

Cost curve for improving efficiency

We progressively apply the energy efficiency improvement options discussed above to the baseline model to estimate the consumption reductions and corresponding 
Table 3 Estimated manufacturing cost vs. efficiency improvement over 100-L baseline

\begin{tabular}{|c|c|c|c|c|}
\hline & $\begin{array}{l}\mathrm{kWh} / \text { year } \\
\left(\text { at } 32^{\circ} \mathrm{C} \text { ) }\right.\end{array}$ & $\begin{array}{l}\text { Energy savings } \\
(\%)\end{array}$ & $\begin{array}{l}\text { Mfg. cost } \\
(\$)\end{array}$ & $\begin{array}{l}\text { Cost increase } \\
(\%)\end{array}$ \\
\hline Baseline (COP 1.4, insulation $3.8 \mathrm{~cm}$ ) & 216 & - & 90 & - \\
\hline Design 1: Insulation thickness $5.8 \mathrm{~cm}$ & 162 & 25 & 105 & 17 \\
\hline Design 2: Design 1 + efficient compressor (COP 1.7) & 130 & 40 & 120 & 33 \\
\hline Design 3: Efficient compressor (COP 1.7) + insulation $9.8 \mathrm{~cm}$ & 104 & 52 & 150 & 67 \\
\hline Design 4: Design 3 + DC VSD compressor & 80 & 63 & 177 & 97 \\
\hline Design 5: Design 4 + VIPs & 64 & 70 & 213 & 137 \\
\hline
\end{tabular}

Note 1: Manufacturing cost here refers to manufacturer selling price

Note 2: The results are based on modeled data; actual manufacturing costs would vary in practice

costs. We apply the design options that have the lowest cost of efficiency improvement (i.e., incremental cost per \% energy savings). Returns on efficiency improvement options diminish as efficiency increases because any efficiency improvement is likely to save much less energy if the refrigerator is already very efficient, in comparison with the same option applied to an inefficient refrigerator.

The bottom-up approach used here generates a costversus-efficiency relationship for refrigerators, including manufacturing costs and costs to the end-user at each level of efficiency corresponding to the design changes discussed above. Note that the analysis presented here provides a reasonable initial estimate of costs for various efficiency improvements but is likely to need further refinement and validation, particularly regarding actual energy consumption levels that can be achieved in the field.

Table 3 and Fig. 3 show that it is possible to reduce the annual electricity consumption of a $100-\mathrm{L}$ refrigerator by about $50 \%$ and $70 \%$ at an incremental cost of about $\$ 60$ and $\$ 120$, respectively. Table 11 and Fig. 9 in Appendix 3 show that the annual electricity consumption of a $50-\mathrm{L}$ refrigerator can be reduced by about $60 \%$ at an incremental cost of about $\$ 100$. We assume retailer markup to be $100 \%$ (a factor of 2) on average, ranging from 50 to $150 \%$ (a factor of 1.5-2.5) based on U.S. DOE (2011) and VHK and ARMINES (2016). ${ }^{9}$ The markup for high-efficiency models on the market may be higher if they are sold as premium products bundled with additional features.

\footnotetext{
${ }^{9}$ Two off-grid focused market development programs, Lighting Global and Global LEAP, use an estimated factor of 1.8. Retail prices are determined by a number of factors; in some cases, prices are not directly determined by manufacturing costs.
}

Figure 4 shows estimated retail price at several annual energy consumption levels in the modeled 50-L and 100$\mathrm{L}$ refrigerators, actual retail prices of refrigerator models with a volume of 45-100 L plotted in Fig. 3. These retail prices appear to be consistent with the price range derived from the bottom-up approach for refrigerators with energy consumption of about $200 \mathrm{kWh} /$ year. We also plotted retail price and energy performance of 13 selected DC refrigeration products whose estimated annual energy consumption (at ambient temperature $32{ }^{\circ} \mathrm{C}$ ) is less than $400 \mathrm{kWh} /$ year and retail price less than $\$ 1000$. According to market research data on DC refrigeration products conducted under the Global LEAP initiative, there seems a wide variation in price and energy consumption of commercially available DC refrigerators and refrigerator-freezers. For example, a DC refrigerator that consumes about $260 \mathrm{kWh} /$ year (at ambient temperature 32 ${ }^{\circ} \mathrm{C}$ ) is sold over $\$ 2000$ (not plotted in Fig. 5), while another DC refrigerator that consumes less than 100 $\mathrm{kWh} /$ year (at ambient temperature $32{ }^{\circ} \mathrm{C}$ ) is available about $\$ 700$ (Global LEAP 2017). Some DC refrigerators or freezers already use highly efficient BLDC compressors and thicker insulation $(11 \mathrm{~cm})$. For example, SunDanzer's refrigerators DCR50 (50 L) and DCR165 (165 L) are claimed to be highly efficient, consuming 114 $\mathrm{Wh} /$ day (42 kWh/year) and $168 \mathrm{Wh} /$ day $(61 \mathrm{kWh} /$ year) at $32.2{ }^{\circ} \mathrm{C}$ ambient temperature, based on the manufacturer's test procedure ${ }^{10}$ (SunDanzer n.d.). However, the price of DC refrigerators or freezers is observed typically more than $\$ 500$, even for very small sizes such as $50 \mathrm{~L}$. DC motors and compressors carry a high premium, in

\footnotetext{
${ }^{10}$ The ambient temperature $32{ }^{\circ} \mathrm{C}$ is consistent with that of the US standard test procedure. However, the authors have no detailed information on the manufacturer's test procedure.
} 


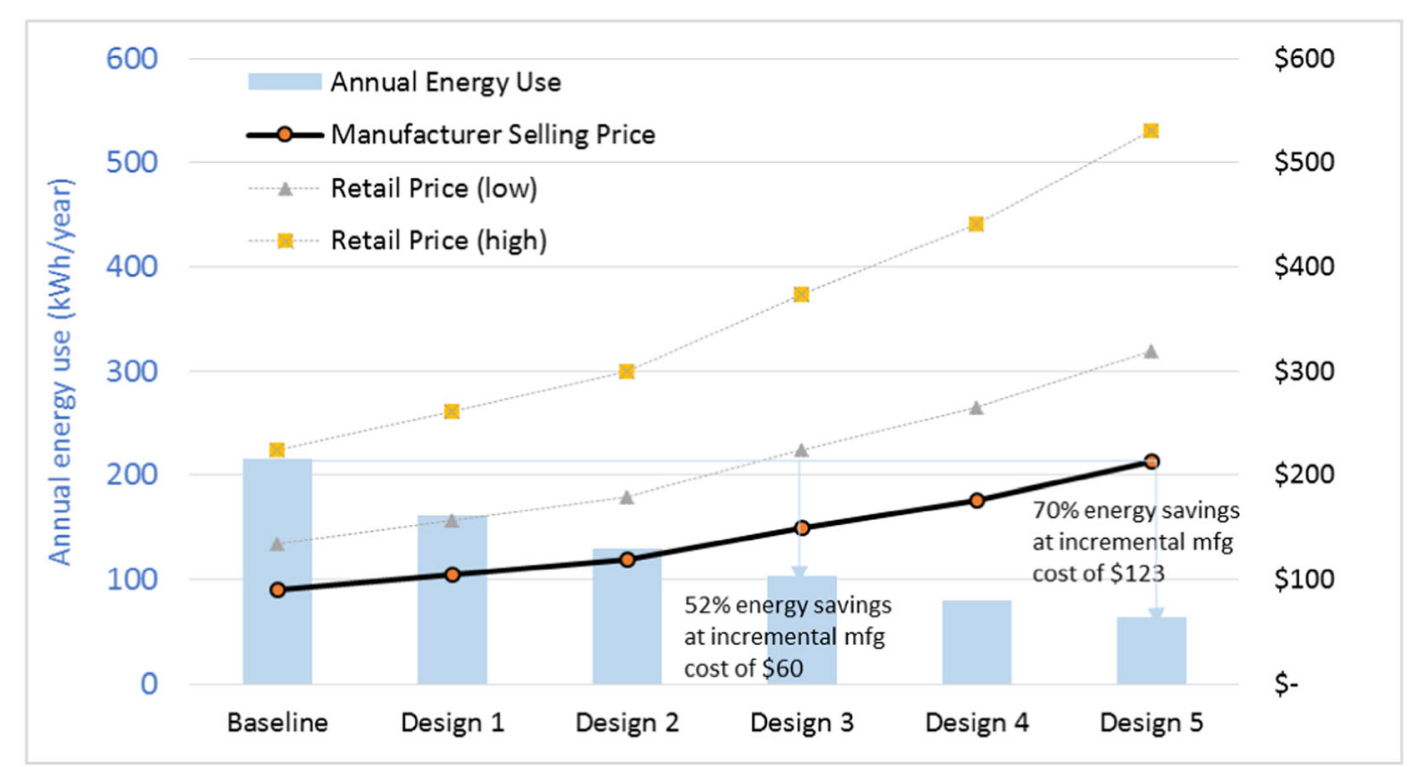

Fig. 3 Estimated incremental cost vs. efficiency improvement over 100-L baseline. We assume that retailer markup is a factor of 1.5-2.5 based on VHK and ARMINES (2016) and U.S. DOE (2011)

part because this is a niche market with a small number of suppliers. Economies of scale are limited because of batch production, which contrasts with continuous production of mainstream refrigeration products. There is a room for further price decreases as manufacturers (particularly those who produce DC motors and compressors) gain experience and expect larger market demand, which would result in economies of scale. Our analysis projects that highly efficient small refrigerators consuming about $100 \mathrm{kWh} /$ year, if deployed at scale, can be made available at about $\$ 150$ or less in manufacturer selling price (or $\$ 300$ or less in retail price).

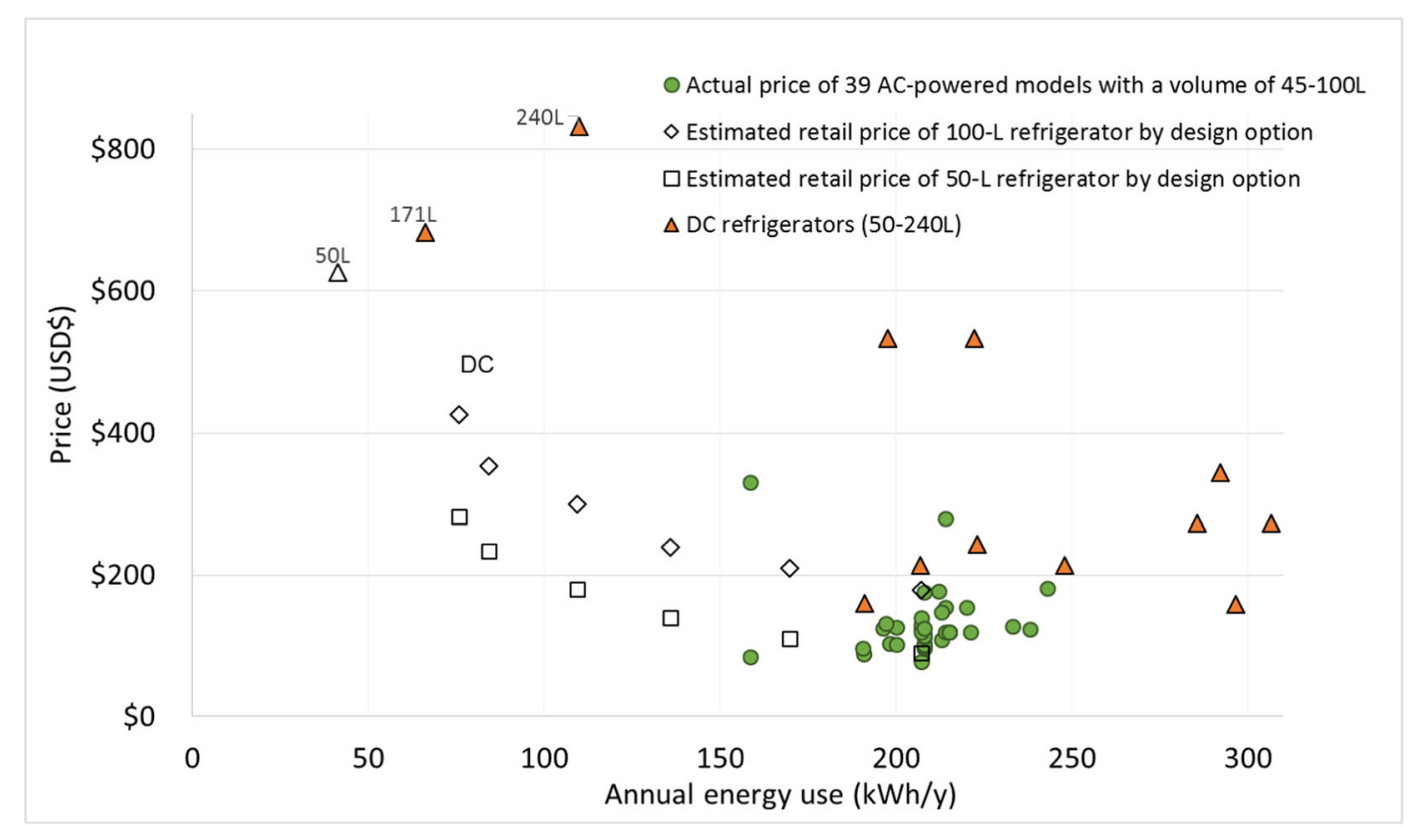

Fig. 4 Estimated annual electricity consumption vs. cost for various refrigerator efficiency levels. Data of 12 DC products were provided by Global LEAP. Data of one DC product (white triangle) were added by authors 
Fig. 5 Annualized cost of SHS with 100 -L refrigerator and $\mathrm{Li}$-ion battery $\left(\boldsymbol{C}_{\boldsymbol{r}}+\boldsymbol{C}_{\boldsymbol{s}}\right)$ at various efficiency levels. Error bars represent annualized costs at discount rate 5\% and 15\%. (See Fig. 10 in Appendix 3 for the results for a $50-\mathrm{L}$ refrigerator)

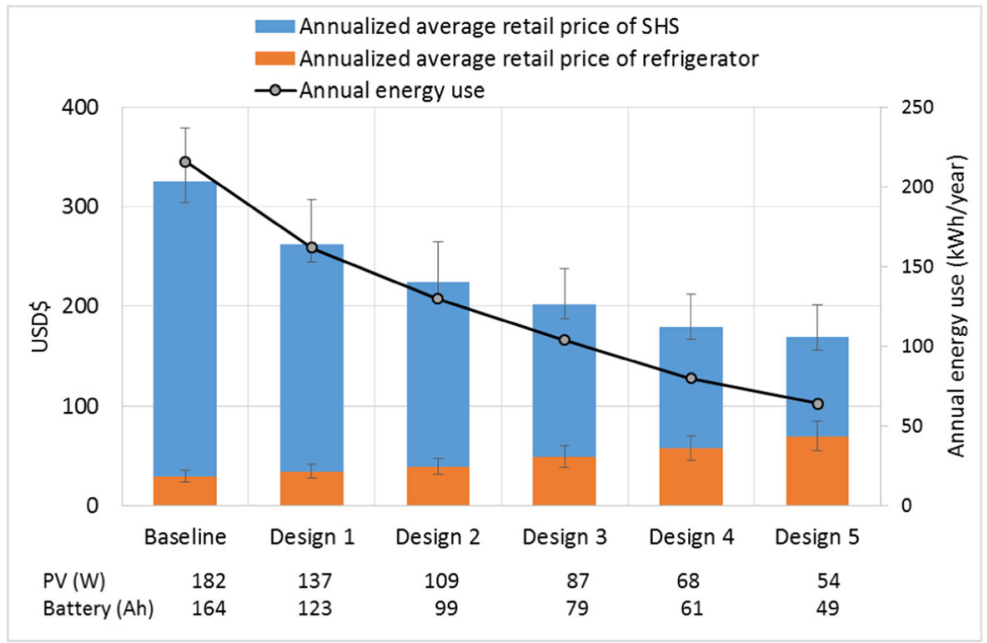

Reducing the annual energy consumption of a refrigerator reduces the size of the SHS required to power the refrigerator. In the next section, we compare the savings from reducing the size of the SHS to the incremental cost of improving the efficiency of the refrigerator.

\section{Potential to reduce the cost of refrigeration service}

Consumers will use refrigeration service if its value is more than its cost. For off-grid consumers, the cost of refrigeration service consists of the upfront cost of the refrigerator and the cost of electricity used by the refrigerator (i.e., the cost of the SHS). We assess how the cost of refrigeration service changes as refrigerator efficiency improves and annual electricity consumption reduces. We define that cost of refrigeration service $\left(\mathrm{Cost}_{\mathrm{rs}}\right)$ as the sum of the annualized costs of the refrigerator $\left(\right.$ Cost $\left._{\mathrm{r}}\right)$ and the SHS (Cost $\left.\mathrm{s}_{\mathrm{s}}\right)$ and the cost of electricity use $\left(\mathrm{Cost}_{\mathrm{e}}\right)$. The up-front cost (nonannualized) of the SHS is available at Appendix 5.

$\operatorname{Cost}_{\mathrm{r} s i}=\operatorname{Cost}_{\mathrm{r} \_i}+\operatorname{Cost}_{\mathrm{s}}+\operatorname{Cost}_{\mathrm{e}}$

where Cost $_{\mathrm{rs}} i$ represents the cost of refrigeration service at annual energy consumption (AEC) with $i$ th design of refrigerator

$\operatorname{Cost}_{\mathrm{r} \_i}=\operatorname{Cost}_{i}\left[\frac{\text { discount rate }}{1-(1+\text { discount rate })^{\text {lifetime }}}\right]$ where Cost $_{\mathrm{r}_{i} i}$ represents the annualized cost of refrigerator to achieve AEC with $i$ th design option discussed above.

$\operatorname{Cost}_{\mathrm{s}_{-j}}=\sum_{j} \operatorname{Cost}_{j}\left[\frac{\text { discount rate }}{1-(1+\text { discount rate })^{\text {lifetime }_{j}}}\right]$

where Cost $_{\mathrm{s}}$ represents the annualized cost of SHS required to power the refrigerator and $j$ does each component of an SHS with a discount rate. Cost $\mathrm{e}_{\mathrm{e}}$ represents the cost of electricity use.

We assume a refrigerator lifetime of 10 years and a discount rate of $10 \%$. These author assumptions are based on U.S. DOE (2011) and Zhuang et al. (2007). According to Zhuang et al. (2007), public discount rates in developing countries range from 8 to $15 \%$. As the effective discount rate for off-grid households and businesses can be much higher, we add a sensitivity analysis for the assumed discount rate. We also assume a battery lifetime of 2 years for a lead-acid battery and 6 years for a lithium (Li)-ion battery and a PV and balance of system (BOS) lifetime of 10 years. These author assumptions are based on Phadke et al. (2015), U.S. AID (2014), and Zhuang et al. (2007).

In general, SHS cost has four components: PV module, battery, balance of system (BOS), and appliances connected to the system. Because total SHS cost is determined mainly by the PV and battery capacities associated with the total connected load, we can analyze system cost by holding constant all variables other than refrigerator efficiency and cost. Key design assumptions for SHSs 
Table 4 Solar home system assumptions

\begin{tabular}{|c|c|c|c|c|c|c|c|}
\hline Characteristics & \multicolumn{7}{|l|}{ Assumptions } \\
\hline Battery efficiency & \multicolumn{7}{|c|}{$80 \%$ (lead-acid), $90 \%$ (Li-ion) } \\
\hline Battery depth of discharge & \multicolumn{7}{|c|}{$70 \%$ (lead-acid), $90 \%$ (Li-ion) } \\
\hline Efficiency losses & \multicolumn{7}{|c|}{$\begin{array}{l}\cdot 15 \% \text { from imperfect maximum power point tracking for the PV module } \\
\text { - } 15 \% \text { from wire resistance, connector contact resistance, and other miscellaneous effects }\end{array}$} \\
\hline Cost of PV module & \multicolumn{7}{|l|}{$\$ 0.5 / \mathrm{W}$} \\
\hline Cost of battery & \multicolumn{7}{|c|}{$\$ 0.06 / \mathrm{Wh}$ (lead-acid), \$0.28/Wh (Li-ion) } \\
\hline Cost of BOS & \multicolumn{7}{|c|}{$<\$ 1.0 / \mathrm{W}-\mathrm{pv}$ (varying by required PV capacity) } \\
\hline \multirow[t]{3}{*}{ Refrigerator } & $100 \mathrm{~L}$ & Baseline & Design 1 & Design 2 & Design 3 & Design 4 & Design 5 \\
\hline & Daily energy use (Wh) & 592 & 444 & 355 & 284 & 220 & 176 \\
\hline & Retail price (USD) & 90 & 105 & 120 & 150 & 177 & 213 \\
\hline
\end{tabular}

Authors' assumptions for battery, PV and BOS are based on Phadke et al. (2015) and U.S. AID (2014). Costs in the table refer to wholesale prices. The results are based on modeled data; actual system sizing would vary in practice

in this analysis include a solar resource of $5 \mathrm{kWh} /$ $\mathrm{m}^{2}$ per day, 3 days of battery storage, a maximum battery depth of discharge of $70 \%$ (for lead-acid battery), and $90 \%$ (for Li-ion battery), as well as the following efficiency losses: $20 \%$ loss (for leadacid battery), $10 \%$ loss (for Li-ion battery) from battery charge-discharge, and about $25 \%$ loss collectively from imperfect maximum power point tracking for the PV module, wire resistance, connector contact resistance, and other miscellaneous effects. Ongoing research in the field of battery chemistry may make lower-cost and higherefficiency options available in the near future.

Table 4 summarizes our SHS assumptions. We note that our assumptions on efficiency loss in SHS are conservative, and well-designed systems could provide better performance. We add a sensitivity analysis for better-designed SHSs (more efficient) than the system defined in Table 4 (see Appendix 4).

A power surge (greater than continuous power) or a high in-rush current (greater than steady-state current) from refrigerators that do not have VSDs must be managed properly to minimize its negative effects and maximize battery life in actual off-grid energy settings (Serdarevic 2012). ${ }^{11}$ Although a technical discussion of high-surge power (typically required when turning on the appliance) and battery management is beyond the scope of this study, there

\footnotetext{
${ }^{11}$ Although batteries can perform reliably when fully charged, a battery at a fraction of its full capacity might be unable to effectively support high start-up or in-rush currents, which could use up battery capacity and result in voltage drop (Serdarevic 2012).
}

are likely to be several relatively low-cost technical solutions to address this issue.

Figure 5 illustrates estimated SHS prices in 2017 by scenario. The estimated prices are retail, including the refrigerators with average retail prices analyzed in the section "Cost curve for improving efficiency." The annualized cost of an SHS with a super-efficient refrigerator is expected to decrease by $46-48 \%$ compared with the cost of the same system with a base-case refrigerator, assuming that the super-efficient refrigerator requires $60 \%$ smaller PV and battery capacity. Although energy-efficient refrigerators cost more than less efficient models, their adoption means that a less-expensive SHS can be installed compared with what would be required to power a less efficient refrigerator. Similar results would apply over a range of system sizes, appliance types, and applications.

Impact of emerging battery technology on solar home system design

Although lead-acid batteries are cheap and commonly used in a variety of applications, they have low efficiency, a small number of life cycles, and maintenance issues, which mean that they must either be much larger in capacity (e.g., 2-4 times) than a Li-ion battery or be replaced earlier (Gretz 2016; U.S. AID 2014; Akhil et al. 2013). The lead-acid battery analyzed above is roughly assumed to operate for 500 to 1000 cycles (or about 1.5 to 3 years) before its capacity drops below $80 \%$, and replacement would be considered. In contrast, the counterpart Li-ion battery is estimated to operate for more 
Table 5 Estimated component specifications for the three solar home system cases

\begin{tabular}{|c|c|c|c|c|c|c|}
\hline Scenario & Battery type & Refrigerator & $\begin{array}{l}\text { Volume } \\
\text { (L) }\end{array}$ & $\begin{array}{l}\text { Total daily load } \\
\text { (Wh/day) }\end{array}$ & $\begin{array}{l}\text { Battery } \\
\text { storage (Ah) }\end{array}$ & $\begin{array}{l}\text { PV module } \\
\text { size }(\mathrm{Wp})\end{array}$ \\
\hline \multirow[t]{2}{*}{ Standard case } & \multirow[t]{2}{*}{ Lead-acid } & \multirow[t]{2}{*}{ Standard (baseline) } & 50 & 567 & 203 & 196 \\
\hline & & & 100 & 592 & 211 & 205 \\
\hline \multirow[t]{2}{*}{ Efficiency case (lead-acid) } & \multirow[t]{2}{*}{ Lead-acid } & \multirow[t]{2}{*}{ Super-efficient (with design 5 in Table 3 ) } & 50 & 209 & 75 & 72 \\
\hline & & & 100 & 176 & 63 & 61 \\
\hline \multirow[t]{2}{*}{ Efficiency case (Li-ion) } & \multirow[t]{2}{*}{ Li-ion } & \multirow[t]{2}{*}{ Super-efficient (with design 5 in Table 3 ) } & 50 & 209 & 58 & 64 \\
\hline & & & 100 & 176 & 49 & 54 \\
\hline
\end{tabular}

Ah ampere hour

(See Table 4 for assumptions.) The results are based on modeled data; actual system sizing would vary in practice

than 2000 cycles (i.e., more than 6 years) without replacement. Thus, the per-cycle cost of Li-ion batteries is reasonably comparable with the per-cycle cost of leadacid batteries. Li-ion batteries also offer several other advantages compared with lead-acid batteries, including smaller size, greater safety, and less environmental impact. The efficiency of Li-ion batteries is improving, and the price is dropping. These advantages make clear why it is important to assess emerging battery technologies, such as Li-ion batteries, as an option for SHSs. If we calculate annualized SHS costs that take equipment lifetime into account, an SHS with a Li-ion battery would become more cost competitive against an SHS with a lead-acid battery.

Table 5 shows estimated component specifications for SHS design by efficiency and battery type. Figure 6 shows annualized costs SHS design scenarios. The two efficiency cases reduce the annualized cost of the SHS by $30-42 \%$ (compared with the cost of the standard case), by reducing the required PV module and battery capacities by $63-76 \%$.

Impact of energy-efficient refrigerators on miniand microgrids

Highly efficient small refrigerators can reduce the cost of refrigeration service in electricity access settings such as mini- or microgrids. Electricity tariffs for mini- or microgrids are significantly higher than those for the central grid, e.g., $\$ 0.15-\$ 0.45 / \mathrm{kWh}$ for mini- or microgrids compared with $\$ 0.07-\$ 0.10$ for central grids in India (McNeil et al. 2011; GNESD 2014; RECP 2014). A highly efficient refrigerator on a mini- or microgrid has the potential, in spite of its higher upfront cost, to reduce the annualized cost of refrigeration service, i.e., the annualized cost of the refrigerator plus cost of electricity use, by up to $17-19 \%$ (13-15\% on average), compared with the cost with an inefficient refrigerator (see Fig. 7 for a 100-L refrigerator and Fig. 11 in the Appendix for a 50-L refrigerator).

We also estimate the cost of conserved electricity (CCE) for comparison with a range of electricity supply costs. The CCE is calculated by dividing the annualized incremental cost (IC) of adding an efficient option by the annual energy savings resulting from the efficient option. The CCE for $i$ th design option (in Table 3 ) is calculated using annualized IC for the $i$ th design option $\left(\mathrm{IC}_{i}\right)$ and energy savings for the $i$ th design option, as follows:

$\mathrm{CCE}_{i}=\frac{\text { annualized } \mathrm{IC}_{i}}{\text { energy savings }}$

where

annualized $\mathrm{IC}_{i}=\mathrm{IC}_{i}\left[\frac{\text { discount rate }}{1-(1+\text { discount rate })^{- \text {lifetime }_{i}}}\right]$

energy savings $_{i}\left(\frac{\mathrm{kWh}}{\text { year }^{\prime}}\right)=\underset{\text {-energy consumption }}{\text { energy case }}$

Lifetime is the refrigerator lifetime, and discount rate is the discount rate of the end-user.

Figure 8 shows CCE by efficiency improvement option and electricity price for mini- or microgrids. The efficiency improvement options analyzed in this study are estimated to have CCEs that are less than an average electricity tariff $\$ 0.3 / \mathrm{kWh}$ on a mini- or microgrid. Thus, refrigerator efficiency on mini- or microgrids can be cost effectively improved beyond the efficiency of standard models. 
Fig. 6 Annualized costs of SHS $\left(\boldsymbol{C}_{\boldsymbol{r}}+\boldsymbol{C}_{\boldsymbol{s}}\right)$, by efficiency scenario and battery type

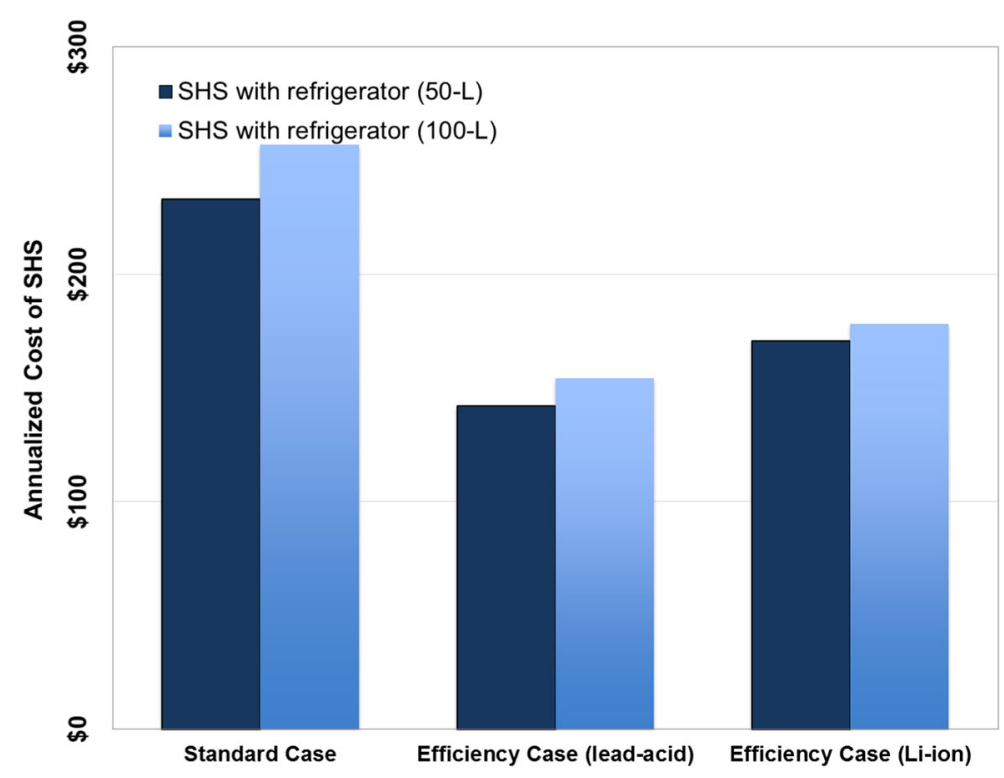

main limitations of providing electricity services using SHSs has been that these systems typically support only lighting and mobile charging. This is in part because the SHS size that would be required to power other devices such as refrigerators would make the SHS unaffordable; hence, a super-efficient refrigerator makes the SHS much more affordable by reducing the SHS size. Given that over 1 billion people worldwide still lack access to electricity, SHSs and mini- or microgrids are likely to be important strategies for meeting electricity access needs. Enabling use of refrigerators with SHSs by drastically reducing refrigerator power requirements could significantly increase access to refrigeration services.
Fig. 7 Annualized cost of refrigeration service $\left(\boldsymbol{C}_{\mathbf{r s}}\right)$ with a 100-L refrigerator on micro/minigrids at various efficiency levels. Assumptions: retailer markup a factor of 2, discount rate $10 \%$ (Zhuang et al. 2007), refrigerator lifetime 10 years (VHK and ARMINES 2016), average electricity tariff $\$ 0.3 / \mathrm{kWh}$ (electricity tariffs range from $\$ 0.15 / \mathrm{kWh}$ to $\$ 0.45 / \mathrm{kWh}$, based on Franz et al. 2014; GNESD 2014; Schnitzer et al. 2014). (See Fig. 10 in Appendix 3 for results for a $50-\mathrm{L}$ refrigerator)

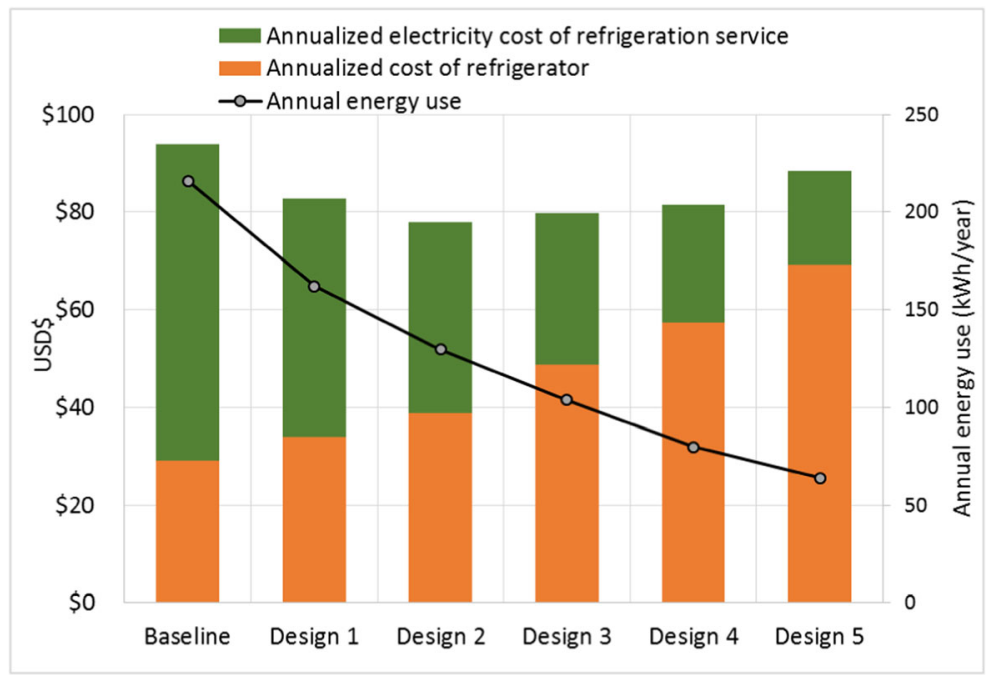




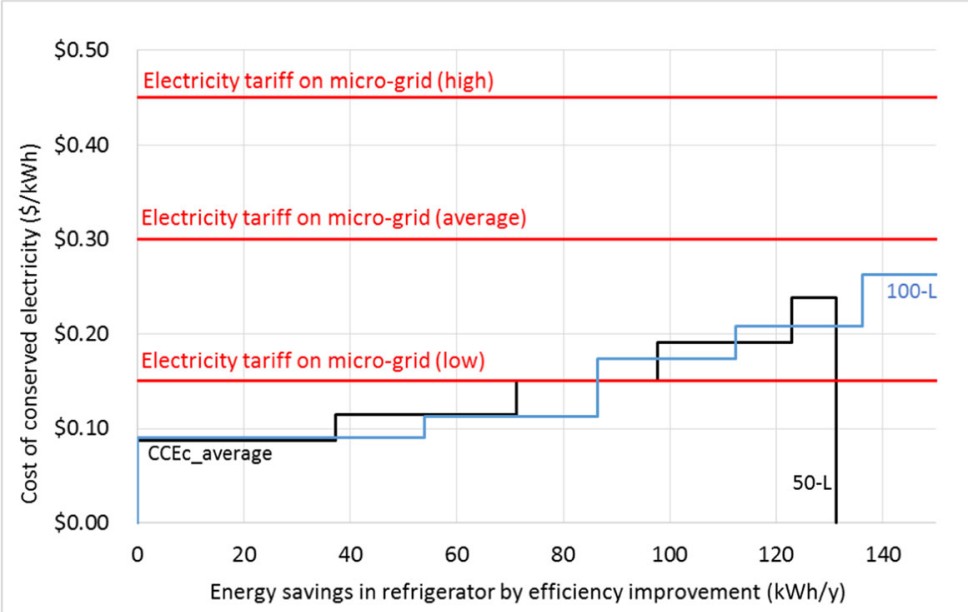

Fig. 8 Cost of conserved electricity at various efficiency levels

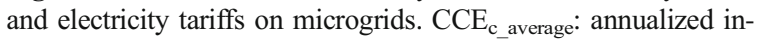
cremental cost to consumer over energy savings. Assumptions for $\mathrm{CCE}_{\mathrm{c} \_ \text {average }}$ : retailer markup a factor of 2 , discount rate $10 \%$
(Zhuang et al. 2007), refrigerator lifetime 10 years (VHK and ARMINES 2016), average electricity tariff $\$ 0.3 / \mathrm{kWh}$ (electricity tariffs range from $\$ 0.15 / \mathrm{kWh}$ to $\$ 0.45 / \mathrm{kWh}$, based on Franz et al. 2014; GNESD 2014; RECP 2014; Schnitzer et al. 2014)
Although highly efficient DC refrigerators are commercially available that require smaller SHSs than would be needed for conventional refrigerators, these DC units are niche products typically costing more than $\$ 500$ and thus are unaffordable for most off-grid consumers. Our analysis shows that if highly efficient small refrigerators can be manufactured at scale, they could sell for $\$ 200$ or less in manufacturer selling price (or $\$ 300$ or less in retail price). Policies and programs are needed to encourage a scale of production that would enable deployment of affordable, quality assured, highly efficient small refrigerators. Programs such as the Global LEAP Awards ${ }^{12}$ can incentivize manufacturers to develop such refrigerators. Procurement incentive programs can enable economies of scale and associated price reductions. Financing, rebates, and pay-as-yougo programs can help address the high-first-cost barrier faced by consumers.

Our analysis provides only a preliminary estimate of the cost and potential to improve the efficiency of small refrigerators. We made several simplifying assumptions because of lack of data. Further research and data are needed to more precisely estimate the potential to

\footnotetext{
${ }^{12}$ Global LEAP launched the first off-grid refrigerator competition, supported by USAID as part of the Scaling Off-Grid Energy Development Grand Challenge, the UK Department for International Development's Ideas to Impact Programme, and Power Africa, and the results are expected to be announced in early 2018. (See details for the competition at http://globalleap.org/awards/)
}

improve efficiency in the context of country- or regionspecific climate conditions and behavioral patterns, taking into account seasonal availability of PV energy output and changes in refrigeration cooling requirements throughout the year.

\section{Compliance with ethical standards}

Conflict of interest The authors declare that they have no conflict of interest.

\section{Appendix 1 Definition of baseline model}

In this analysis, we assumed one $50-\mathrm{L}$ and one $100-\mathrm{L}$ single-door baseline refrigerator models to estimate costefficiency relationships for off- and micro/mini-grid uses. The key specifications of the baseline models are adjusted from those of two "category 1" basic technical models (42-L and 107-L refrigerators) described in a recent EU study (VHK and ARMINES 2016). Table 6 summarizes the key specifications.

Volume, envelope surface, and wall thickness

We assumed two baseline models (50-L and 100-L) with an average wall thickness of $3.8 \mathrm{~cm}$ (1.5 in.) and calculated the refrigerator envelope surface areas by adjusted size and wall thickness. 
Table 6 Characteristics of off-grid baseline refrigerator models

\begin{tabular}{|c|c|c|c|c|c|}
\hline & & $\begin{array}{l}\text { Europe, VHK } \\
\text { and ARMINES } \\
(2016)\end{array}$ & $\begin{array}{l}\text { LBNL 50-L } \\
\text { (single-door } \\
\text { refrigerator) }\end{array}$ & $\begin{array}{l}\text { Europe, VHK } \\
\text { and ARMINES } \\
(2016)\end{array}$ & $\begin{array}{l}\text { LBNL 100-L } \\
\text { (single-door } \\
\text { refrigerator) }\end{array}$ \\
\hline \multicolumn{2}{|l|}{ Refrigerated volume (L) } & 42 & 50 & 107 & 100 \\
\hline \multicolumn{2}{|l|}{ Width $(\mathrm{cm})$} & 45 & 48 & 52 & 48 \\
\hline \multicolumn{2}{|l|}{ Depth (cm) } & 47 & 48 & 52 & 48 \\
\hline \multicolumn{2}{|l|}{ Height (cm) } & 52 & 55 & 80 & 85 \\
\hline \multicolumn{2}{|l|}{ Refrigerator envelop surface $\left(\mathrm{m}^{2}\right)$} & 1.00 & 1.11 & 1.72 & 1.64 \\
\hline \multicolumn{2}{|l|}{ Average wall thickness (cm) } & 3.6 & 3.8 & 4.1 & 3.8 \\
\hline \multicolumn{2}{|l|}{ Nominal compressor power (W) } & 45 & 55 & 45 & 55 \\
\hline \multicolumn{2}{|l|}{ Compressor COP $(\mathrm{W} / \mathrm{W})$} & 1.7 & 1.4 & 1.7 & 1.4 \\
\hline \multirow[t]{3}{*}{$\begin{array}{l}\text { Annual electricity consumption } \\
(\mathrm{kWh} / \text { year })\end{array}$} & $\begin{array}{l}\text { Per refrigerated volume } \\
\text { (based on EU test standard) }\end{array}$ & 1.8 & 2.3 & 0.8 & 1.2 \\
\hline & $\begin{array}{l}\text { Based on EU test standard } \\
\text { (ambient temperature } \\
\left.25^{\circ} \mathrm{C}\right)\end{array}$ & 78 & 115 & 83 & 120 \\
\hline & $\begin{array}{l}\text { Based on US test standard } \\
\text { (ambient temperature } \\
\left.32{ }^{\circ} \mathrm{C}\right)\end{array}$ & - & 207 & - & 216 \\
\hline
\end{tabular}

Compressor COP and cooling power

We assess the compressor efficiency (COP 1.7) of the EU basic technical models to be relatively high for small refrigerators. Commercially available single-speed compressors used in small refrigerators (e.g., with capacity less than 75 $\mathrm{W},<250 \mathrm{Btu} / \mathrm{h}$ ) were assessed to be significantly less efficient than the typical compressors used in larger size refrigerators, e.g., COP 1.0 or less (VHK and ARMINES 2016; U.S. DOE 2011). However, in Europe, similar size compressors (R600a iso-butane) with COP 1.4 or above were available in 2015 (VHK and ARMINES 2016). VHK and ARMINES (2016) integrated category 1 and other relevant product categories into a new product category, "COLD 1," and assumed the COP of the baseline COLD 1 product (which is approximately $250 \mathrm{~L}$ and uses an approximately $60-\mathrm{W}$ compressor) to be about 1.6 . In this analysis, we assumed the compressor COP of the baseline products is 1.4 based on the findings from VHK and ARMINES (2016). Accordingly, the cooling power of the baseline models increase compared with the cooling power of the models studies in VHK and ARMINES (2016).

Annual energy consumption

The annual energy consumption per refrigerated volume for the EU basic technical model is estimated to be 1.8
$\mathrm{kWh} / \mathrm{L}$ for a $42-\mathrm{L}$ unit and $0.8 \mathrm{kWh} / \mathrm{L}$ for a $107-\mathrm{L}$ unit (VHK and ARMINES 2016). (Energy consumption per volume of small refrigerators is greater than energy consumption per volume of large refrigerators.) However, the 42-L technical model is assessed to be more efficient than both the EU label A+threshold and a statistical regression result from data on commercially available products (VHK and ARMINES 2016). In this analysis, we used the curve expressed in Eq. (7) from VHK and ARMINES (2016), which is close to the EU label A+ threshold, resulting in $2.3 \mathrm{kWh} / \mathrm{L}$ and $1.2 \mathrm{kWh} /$ L for our baseline 50-L and 100-L models, respectively. Note that EU label A+-qualified models, except for wine coolers, accounted for about $70 \%$ of the European market in 2014 (VHK and ARMINES 2016).

Annual Energy Consumption $\left(\frac{\mathrm{kWh}}{\mathrm{L}}\right)=110 \times$ Volume $^{-1}+0.1$

Equation (7) is based on the EU test standard with ambient temperature of $25{ }^{\circ} \mathrm{C}$. We use an adjustment factor of 1.8 to scale energy use from a test standard based on IEC 62252:2007 (test ambient temperature $25^{\circ} \mathrm{C}$ ) to the US standard (test ambient temperature $32{ }^{\circ} \mathrm{C}$ ), based on the findings from APEC (2016). As the result, the estimated annual 
electricity consumption based on the US test standard with an ambient temperature $32{ }^{\circ} \mathrm{C}$ is 207 $\mathrm{kWh} /$ year for the $50-\mathrm{L}$ baseline model and 216 $\mathrm{kWh} /$ year for the $100-\mathrm{L}$ baseline model. These are about $11-12 \%$ more efficient than the US MEPS for compact refrigerators with manual defrost (233 $\mathrm{kWh} /$ year for $50 \mathrm{~L}$ and $247 \mathrm{kWh} /$ year for $100 \mathrm{~L}$ ).

\section{Appendix 2 Development of cost-efficiency relationship in refrigerators}

Increasing insulation thickness

Increase in insulation thickness results in decreased interior volume, increased exterior cabinet dimensions, or a combination of both, which affects incremental cost and consumer utility (U.S. DOE 2011). Wall thickness cannot increase indefinitely. Limited spaces for refrigerators restrict how much exterior product size can increase, and reducing interior volume is considered undesirable because it affects consumer utility (U.S. DOE 2011). For these reasons, U.S. DOE (2011) did not consider a significant increase in insulation thickness (see Table 7). However, commercially available energy-efficient DC refrigerators use thick insulation, e.g., $11-\mathrm{cm}$ polyurethane for SunDanzer's DCR50 and DCF 50, which suggests that increased volume may not be as much of a constraint in the off-grid market as the on-grid market. Benefit from VIPs can also be obtained by increasing insulation thickness. We here assume that insulation can be increased up to $10 \mathrm{~cm}$ with concomitant increased exterior dimensions, based on practical limits estimated by previous studies (VHK and ARMINES 2016; U.S. DOE 2011).

To estimate the costs of increasing insulation thickness (resulting in increased exterior product dimensions) and corresponding reduction in energy consumption, we adjust estimates from other studies. According to U.S. DOE (2011), the materials cost for a $2-\mathrm{cm}$ increase in insulation thickness is \$2.6-3.4 (for products of 50 to $110 \mathrm{~L}$ ), and the largest share of the total incremental cost of $\$ 16$ comes from depreciation $(\$ 10)$, which would require redesign of the entire refrigerator platform, likely requiring that a new production plant be built. VHK and ARMINES (2016) also assumed

Table 7 Energy savings and incremental costs resulting from increasing insulation thickness

\begin{tabular}{|c|c|c|c|c|}
\hline & Detailed description & Baseline model (L) & $\%$ energy savings & $\begin{array}{l}\text { Incremental } \\
\text { cost }(\$)\end{array}$ \\
\hline VHK and ARMINES (2016) & $\begin{array}{l}\text { Additional } 1 \mathrm{~cm}(4.7 \text { to } 5.7 \mathrm{~cm}) \\
\text { Additional } 2 \mathrm{~cm}(4.7 \text { to } 6.7 \mathrm{~cm}) \\
\text { Additional } 3 \mathrm{~cm}(4.7 \text { to } 7.7 \mathrm{~cm}) \\
\text { Additional } 5.3 \mathrm{~cm}(4.7 \text { to } 10 \mathrm{~cm})\end{array}$ & 247 & $\begin{array}{l}11 \\
23 \\
31 \\
40\end{array}$ & $\begin{array}{l}13 \\
28 \\
42 \\
79\end{array}$ \\
\hline \multirow[t]{2}{*}{ U.S. DOE (2011) } & Additional $1.9 \mathrm{~cm}$ to cabinet & $\begin{array}{l}48 \\
113\end{array}$ & $\begin{array}{l}13 \\
20\end{array}$ & $\begin{array}{l}16 \\
17\end{array}$ \\
\hline & Additional $1.9 \mathrm{~cm}$ to door & $\begin{array}{l}48 \\
113\end{array}$ & $\begin{array}{l}<6 \\
6\end{array}$ & $\begin{array}{l}4.5 \\
4.9\end{array}$ \\
\hline \multirow[t]{2}{*}{ Authors' assumptions for this study } & Additional $2 \mathrm{~cm}(3.8$ to $5.8 \mathrm{~cm})$ to door/wall & $\begin{array}{l}50 \\
100\end{array}$ & $\begin{array}{l}18 \\
25\end{array}$ & $\begin{array}{l}10 \\
15\end{array}$ \\
\hline & Additional $6 \mathrm{~cm}(3.8$ to $9.8 \mathrm{~cm})$ to door/wall & $\begin{array}{l}50 \\
100\end{array}$ & $\begin{array}{l}34 \\
40\end{array}$ & $\begin{array}{l}30 \\
45\end{array}$ \\
\hline
\end{tabular}

We assumed \$ $1=1.1$ EURO and estimated the incremental cost based on the incremental price; i.e., the manufacturing cost of the baseline in VHK and ARMINES (2016) accounts for about $41 \%$ of the estimated market price

Percent energy savings are authors' estimates at an aggregate level based on insulation-specific design options from U.S. DOE (2011). For example, if increasing door insulation by $1.9 \mathrm{~cm}$ improves the baseline model's efficiency from $20 \%$ (a level already achieved by other options) to $25 \%$ (a level that can be achieved by increasing insulation), this translates to an energy consumption decrease of about $6 \%, 0.8$ to 0.75 . The energy savings from additional door and cabinet insulation is calculated by $100 \%-(100 \%-13 \%) \times(100 \%-6 \%)=18 \%$ 
that an increase in insulation thickness results in increased exterior cabinet dimensions. The study estimated increasing insulation up to $10 \mathrm{~cm}$ to reduce energy consumption up to $29-41 \%$ by product type and specifications (VHK and ARMINES 2016).

Although the baseline compact refrigerator models defined in U.S. DOE (2011) have similar sizes and specifications to those of our baseline models, the depreciation cost for potentially building a new production facility is not appropriate to use in this analysis. The estimated envelope surface areas of the 50-L and 100-L baseline models are about $36 \%$ and $53 \%$ of that of the $247-\mathrm{L}$ model in VHK and ARMINES (2016). According to VHK and ARMINES (2016), the incremental cost required to increase insulation thickness by $1 \mathrm{~cm}$ is about $\$ 13-\$ 15$. Based on this relationship, we assume that the efficiency rates of our $50-\mathrm{L}$ and $100-\mathrm{L}$ baseline refrigerators improve by $18 \%$ and $25 \%$, respectively, from increasing insulation thickness by $2 \mathrm{~cm}$ (see Table 7 for details). The incremental cost associated with this is calculated by $\$ 14 \times 2 \mathrm{~cm} \times 36 \%=\$ 10.1$ for the $50-\mathrm{L}$ model and $\$ 14 \times 2 \mathrm{~cm} \times 53 \%=\$ 14.8$ for the $100-\mathrm{L}$ model.
Vacuum insulation panels

Typically, 2-cm-thick VIPs are used to replace standard insulation. VIPs are estimated to reduce energy consumption collectively by $23 \%$ for the 247-L base-case model in VHK and ARMINES (2016). This improvement can be achieved without increasing insulation thickness. U.S. DOE (2011) estimated an efficiency improvement potential from adding VIPs to increase refrigerator insulation, but U.S. DOE's estimated incremental costs appear outdated compared with those in VHK and ARMINES (2016).

The baseline compact refrigerator models defined in U.S. DOE (2011) are similar in size and specifications to our baseline models, so we assume that adding VIPs of similar size to those applied in U.S. DOE (2011) can reduce the energy consumption by $10-20 \%$. We estimate the size of VIPs used in VHK and ARMINES (2016) to be $5481 \mathrm{~cm}^{2}\left(70 \%\right.$ of $\left.7830 \mathrm{~cm}^{2}\right)$ and the manufacturing cost to be $\$ 0.004 / \mathrm{cm}^{2}$. We assume that adding $4000 \mathrm{~cm}^{2}$ ( $\sim 70 \%$ of door covered) of VIPs in the cabinet and $1850 \mathrm{~cm}^{2}(\sim 50 \%$ of lateral and back sides covered) of VIPs to the door would cost about $\$ 24$ for our 50-L baseline model and that

Table 8 Energy savings and incremental costs by using vacuum insulation panels

\begin{tabular}{|c|c|c|c|c|}
\hline & Detailed description & Baseline model (L) & $\begin{array}{l}\text { \% energy } \\
\text { savings }\end{array}$ & $\begin{array}{l}\text { Incremental } \\
\text { cost }(\$)\end{array}$ \\
\hline \multirow[t]{2}{*}{ VHK and ARMINES (2016) } & Use of VIPs, $70 \%$ of door covered & 247 & 8 & 24 \\
\hline & Use of VIPs, $50 \%$ of lateral and back sides covered & & 16 & 50 \\
\hline \multirow[t]{2}{*}{ U.S. DOE (2011) } & $\begin{array}{l}\text { Add } 4.7 \mathrm{ft}^{2}\left(4366 \mathrm{~cm}^{2}\right) \text { in cabinet } \\
\text { Add } 2.2 \mathrm{ft}^{2}\left(2044 \mathrm{~cm}^{2}\right) \text { in door }\end{array}$ & 48 & 10 & 41 \\
\hline & $\begin{array}{l}\text { Additional } 0.8 \mathrm{~cm} \text { insulation in cabinet } \\
\text { Add } 7.2 \mathrm{ft}^{2}\left(6689 \mathrm{~cm}^{2}\right) \text { in cabinet } \\
\text { Add } 4.2 \mathrm{ft}^{2}\left(3902 \mathrm{~cm}^{2}\right) \text { in door }\end{array}$ & 113 & 24 & 66 \\
\hline \multirow[t]{2}{*}{ Authors' assumptions for this study } & $\begin{array}{l}\text { Add } 4000 \mathrm{~cm}^{2} \text { in cabinet } \\
\text { Add } 1850 \mathrm{~cm}^{2} \text { in door }\end{array}$ & 50 & 10 & 24 \\
\hline & $\begin{array}{l}\text { Add } 6100 \mathrm{~cm}^{2} \text { in cabinet } \\
\text { Add } 2850 \mathrm{~cm}^{2} \text { in door }\end{array}$ & 100 & 20 & 36 \\
\hline
\end{tabular}

We assumed 1 USD = 1.1 EURO and estimated the incremental cost based on the incremental price; i.e., the manufacturing cost of the baseline in VHK and ARMINES (2016) accounts for about $41 \%$ of the estimated market price

$\%$ energy savings from U.S. DOE (2011) are authors' estimates at an aggregate level based on VIP-specific design options. For example, if adding VIPs of $4.7 \mathrm{ft}^{2}$ in cabinet and $2.2 \mathrm{ft}^{2}$ in door improves efficiency of the baseline model from $50 \%$ (a level already achieved by other options) to $55 \%$ (a level that can be achieved by adding VIPs), the associated energy consumption decreases by $10 \%$, e.g., 0.5 to 0.45 
Table 9 Energy savings and incremental costs by compressor efficiency improvement

\begin{tabular}{|c|c|c|c|c|}
\hline & Detailed description & $\begin{array}{l}\text { Baseline } \\
\text { model (L) }\end{array}$ & $\begin{array}{l}\% \text { energy } \\
\text { savings }\end{array}$ & $\begin{array}{l}\text { Incremental } \\
\text { cost }(\$)\end{array}$ \\
\hline \multirow{2}{*}{$\begin{array}{l}\text { VHK and ARMINES } \\
\text { (2016) }\end{array}$} & Increase compressor (COP 1.64 to $1.72 \mathrm{~W} / \mathrm{W}$ ) & \multirow[t]{2}{*}{247} & 5 & 4.4 \\
\hline & Increase compressor (COP 1.64 to $1.85 \mathrm{~W} / \mathrm{W})$ & & 12 & 11.2 \\
\hline \multirow[t]{2}{*}{ U.S. DOE (2011) } & $\begin{array}{l}\text { Increase compressor-energy-efficiency ratio (EER) } 3.20 \text { to } 3.47 \\
(\mathrm{Btu} / \mathrm{h}) / \mathrm{W}(\mathrm{COP} 0.94 \text { to } 1.01 \mathrm{~W} / \mathrm{W})\end{array}$ & 48 & 5.5 & 3.4 \\
\hline & $\begin{array}{l}\text { Increase compressor EER } 4.57 \text { to } 5.1(\mathrm{Btu} / \mathrm{h}) / \mathrm{W}(\mathrm{COP} 1.34 \mathrm{t} \\
\text { o } 1.5 \mathrm{~W} / \mathrm{W})\end{array}$ & 113 & 10 & 6.7 \\
\hline $\begin{array}{l}\text { Authors' assumptions } \\
\text { for this study }\end{array}$ & Increase compressor COP 1.4 to $1.7(\mathrm{~W} / \mathrm{W})$ & $\begin{array}{l}50 \\
100\end{array}$ & 20 & 15.0 \\
\hline
\end{tabular}

We assumed 1 USD = 1.1 EURO and estimated the incremental cost based on the incremental price; i.e., the manufacturing cost of the baseline in VHK and ARMINES (2016) accounts for about $41 \%$ of the estimated market price

$\%$ energy savings from U.S. DOE (2011) are authors' estimates based on compressor-specific design options

adding $6100 \mathrm{~cm}^{2}(\sim 70 \%$ of door covered) of VIPs in the cabinet and $2850 \mathrm{~cm}^{2}(\sim 50 \%$ of lateral and back sides covered) of VIPs in the door would cost about $\$ 36$ for our 100-L baseline model.

\section{Efficient compressors}

As discussed earlier, we assumed the compressor COP of our baseline products to be 1.4 based on findings from VHK and ARMINES (2016). According to VHK and ARMINES (2016), compressors with COP 1.7 are available for all cooling capacities. The incremental costs for efficient compressors are estimated to be about $\$ 4-\$ 5$ for 0.1 improvement in nominal COP $(\mathrm{W} / \mathrm{W})$ based on VHK and ARMINES (2016) and U.S. DOE (2011). We assume that the compressor efficiency improvement (COP 1.4 to $1.7 \mathrm{~W} / \mathrm{W}$ ) can reduce the energy consumption by $20 \%$ at an incremental cost of $\$ 15$.

\section{Variable-speed drives}

U.S. DOE (2011) estimated a VSD compressor alone to improve energy efficiency by $35 \%$ at an incremental cost of \$44. According to VHK and ARMINES (2016), COP and minimum capacity that can be achieved with VSD compressors vary with size of refrigerator. The study estimated that adding a VSD to base-case models reduced energy consumption by $11-28 \%$ by product category, e.g., $11 \%$ for a $247-\mathrm{L}$ model. VSD compressors typically use a permanent-magnet DC motor instead of the induction motor used in a single-speed AC compressor. DC motors for VSD compressors require additional electronics compared with AC motors. Although it is difficult to precisely estimate the cost difference between DC motors and AC motors, the controls for a DC motor require additional electronics costing an additional \$10-\$20 (Shah et al. 2014a, b). According to comments from an industrial expert, a VSD alone can improve energy efficiency by $10-12 \%$. While DC compressors are still very expensive in market price, a $\$ 10-\$ 20$ inverter package that converts $\mathrm{DC}$ into $\mathrm{AC}$ makes it possible to use an $\mathrm{AC}$ compressor with the inverter combined. This cheaper solution is already commercially available. Here, we assume that a VSD compressor with BLDC motor improves efficiency, compared with an equivalent efficient AC compressor, by an average of $23 \%$ at an average incremental cost of $\$ 27$. Based on VHK and ARMINES (2016), Shah et al. (2014a, b), and U.S. DOE (2011), efficiency improvements range from 10 to $35 \%$, and incremental costs range from $\$ 10$ to $\$ 44$.

Table 10 Energy savings and incremental costs for variablespeed drives

\begin{tabular}{llll}
\hline & $\begin{array}{l}\text { Baseline } \\
\text { model (L) }\end{array}$ & $\begin{array}{l}\text { \% energy } \\
\text { savings }\end{array}$ & $\begin{array}{l}\text { Incremental } \\
\text { cost }(\$)\end{array}$ \\
\hline $\begin{array}{l}\text { VHK and ARMINES } \\
\quad 247\end{array}$ & 11 & 9 \\
$\begin{array}{l}\text { U.S. DOE (2011) } \\
\begin{array}{l}\text { Authors' assumptions } \\
\text { for this study }\end{array}\end{array}$ & 50,100 & $10-35$ & $10-44$ \\
\hline
\end{tabular}




\section{Appendix 3 Analysis results for 50-L refrigerators}

Table 11 Estimated incremental cost vs. efficiency improvement compared with 50-L baseline

\begin{tabular}{|c|c|c|c|c|}
\hline & $\mathrm{kWh} /$ year $\left(32^{\circ} \mathrm{C}\right)$ & Energy savings $(\%)$ & Mfg. cost (\$) & Cost increase $(\%)$ \\
\hline Baseline (COP 1.4, insulation $3.8 \mathrm{~cm}$ ) & 207 & - & 45 & - \\
\hline Design 1: insulation thickness $5.8 \mathrm{~cm}$ & 170 & 18 & 55 & 22 \\
\hline Design 2: design $1+$ efficient compressor (COP 1.7) & 136 & 34 & 70 & 56 \\
\hline Design 3: efficient compressor (COP 1.7) + insulation $9.8 \mathrm{~cm}$ & 109 & 47 & 90 & 100 \\
\hline Design 4: design $3+$ DC VSD compressor & 85 & 59 & 117 & 160 \\
\hline Design 5: design $4+$ VIPs & 76 & 63 & 141 & 213 \\
\hline
\end{tabular}

Manufacturing cost here possibly corresponds to wholesale price or factory gate price

The results are based on modeled data; actual manufacturing cost would vary in practice

Fig. 9 Estimated incremental compared with 50-L baseline. Note: We assume retailer markup is a factor of 1.5-2.5 based on VHK and ARMINES 2016 and U.S. DOE 2011. Error bars represent annualized costs at discount rate $5 \%$ and $15 \%$ cost vs. efficiency improvement

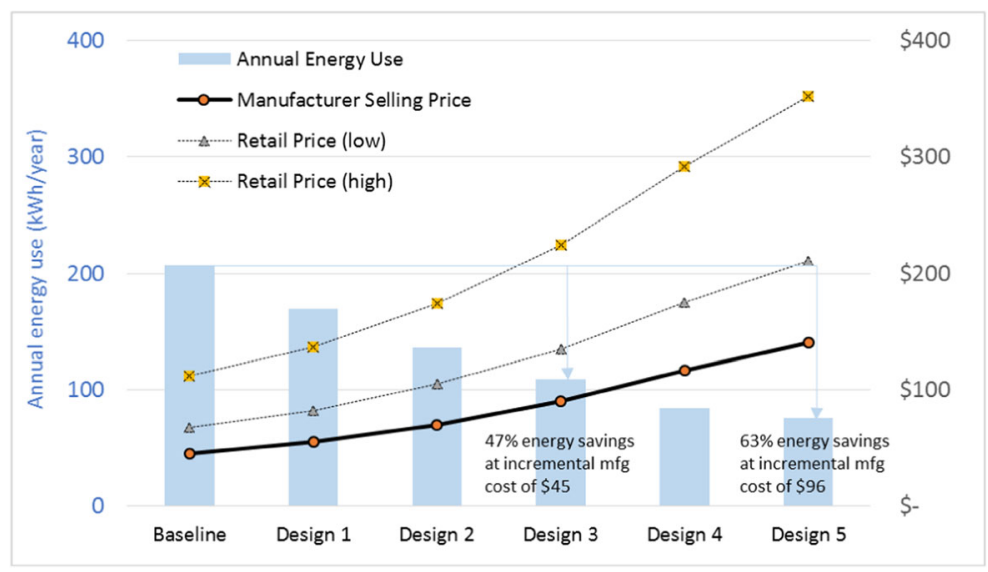

Fig. 10 Annualized cost of SHS with a $50-\mathrm{L}$ refrigerator and $\mathrm{Li}$ ion battery $\left(\boldsymbol{C}_{\mathbf{r}}+\boldsymbol{C}_{\mathbf{s}}\right)$ at various efficiency levels

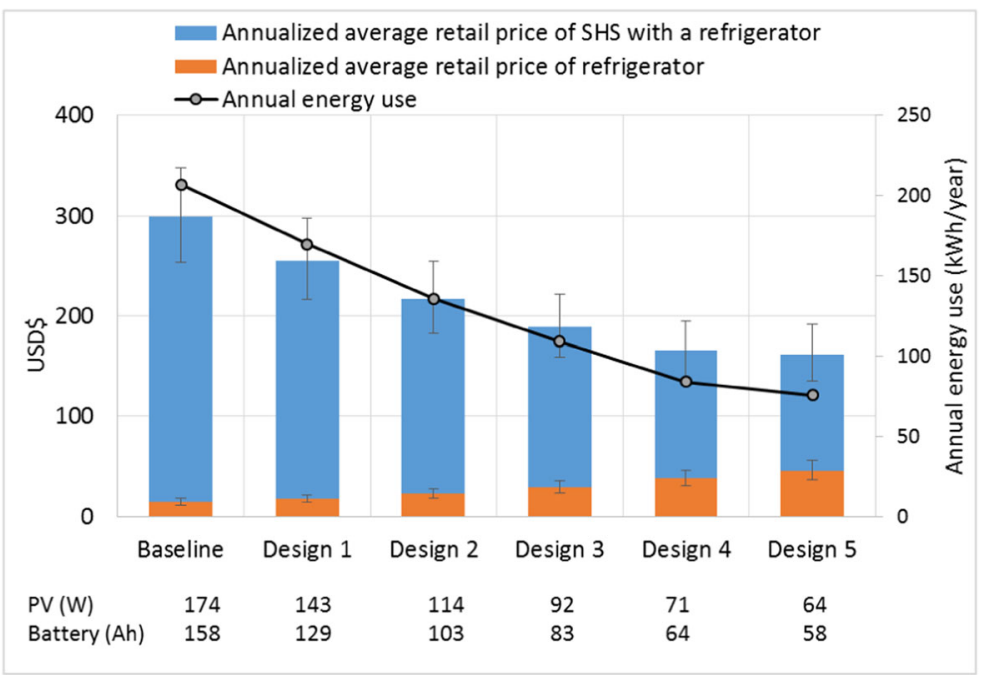


Fig. 11 Annualized cost of refrigeration service $\left(\boldsymbol{C}_{\mathbf{r s}}\right)$ with a 50-L refrigerator on micro/minigrids at various efficiency levels

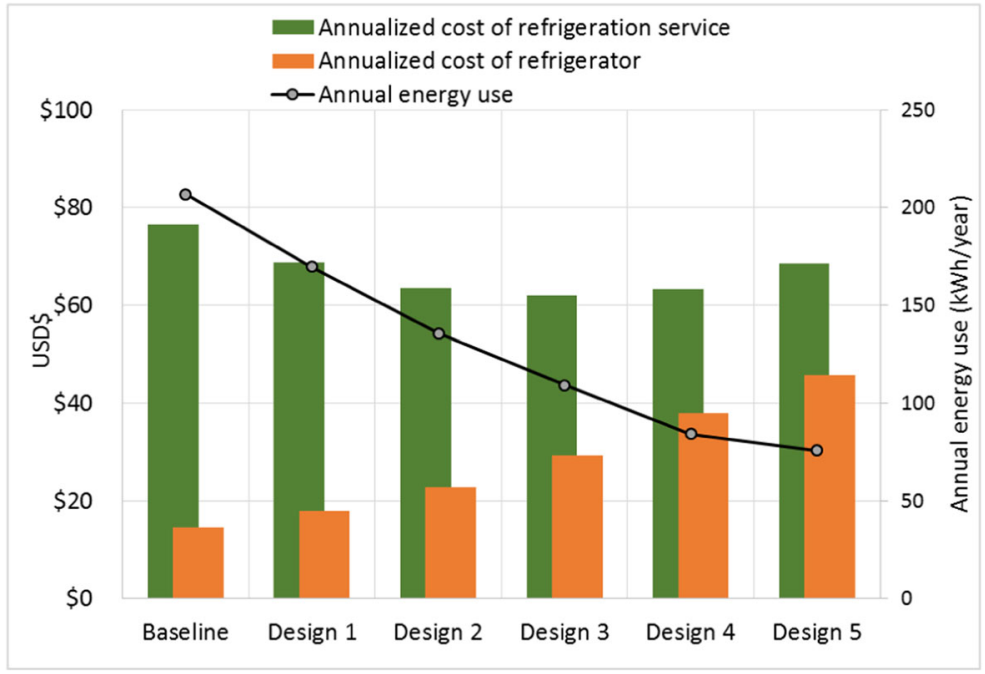

\section{Appendix 4 Sensitivity of our findings to key assumptions}

Our key finding is that the cost of refrigeration service can be reduced significantly by improving refrigerator efficiency. This is because the cost of the efficiency improvement is less than the savings from lowered electricity bills or smaller SHSs needed to power-efficient refrigerators compared with the costs and SHS size associated with less efficient refrigerators. There is some uncertainty about the cost of several efficiency options we discuss as well as the consumption reductions from these efficiency options. Therefore, we assess the sensitivity of our results to higher incremental efficiency improvement costs and smaller energy savings than we assume in our analysis.

Specifically, we assess whether the cost of refrigeration service can be reduced even if the efficiency improvements realized were $25 \%$ less than our assumptions (e.g., if the energy savings potential of a VSD compressor were $17 \%$, which is $25 \%$ lower than the $23 \%$ that we assumed), and if the incremental cost of energy efficiency improvement is $25 \%$ higher than our estimates (e.g., if the incremental cost of a VSD compressor were $\$ 34$, which is $25 \%$ higher than the $\$ 27$ assumed in our analysis). Further, we assess whether our findings still hold true if the cost of SHSs is $25 \%$ lower than we assumed, (e.g., if PV cost was $\$ 0.38 / \mathrm{W}$, which is $25 \%$ lower than the $\$ 0.50 / \mathrm{W}$ assumed in our analysis).

Figures 12 and 13 show annualized costs at discount rate $11.5 \%$ of refrigeration service under these alternative assumptions about costs and efficiency improvement. If the efficiency improvements realized were $25 \%$ less than our assumptions, the annualized cost of SHSs would increase by $5-24 \%$ for $50-\mathrm{L}$ units and $6-21 \%$ for $100-\mathrm{L}$ units, depending on design options, compared with the case analyzed in "Potential to reduce the cost of refrigeration service" section (see green dotted lines in Figs. 12 and 13). If the cost of SHSs were $25 \%$ lower than we assumed, the annualized cost of SHSs would decrease by 15 $22 \%$ for $50-\mathrm{L}$ units and $12-20 \%$ for $100-\mathrm{L}$ units, depending on design options, compared with the case analyzed in Section 3.2 (see purple dotted lines in Figs. 12 and 13). The more efficient SHS with MPPT efficiency $95 \%$ and other efficiency $95 \%$ and the $25 \%$ higher incremental cost of energy efficiency improvements do not significantly change the annualized cost of SHSs (see blue and red dotted lines in Figs. 12 and 13). Figures 14, 15, 16, and 17 show annualized costs of refrigeration service under the same assumptions at discount rate of $8 \%$ and $15 \%$. 
Fig. 12 Cost of refrigeration service with a 50-L refrigerator under alternative assumptions about cost and efficiency improvement. Discount rate $11.5 \%$

Fig. 13 Cost of refrigeration service with a 100 -L refrigerator under alternative assumptions about cost and efficiency improvement. Discount rate $11.5 \%$
Annualized cost of SHS

- Annualized cost of SHS with $25 \%$ lower EE improvement

$-\bullet-$ Annualized cost of SHS with $25 \%$ higher incremental cost of EE improvement

$\$ 400$

- Annualized cost of SHS with $25 \%$ lower cost of SHS (PV and Battery)

- - Annualized cost of SHS with more efficient SHS (MPPT efficiency 95\%, Other efficiency 95\%)

$\$ 350$

$\$ 300$

$\$ 250$

$\$ 200$

$\$ 150$

$\$ 100$

$\$ 50$

$\$-$

$\begin{array}{llllll}\text { Baseline Design } 1 & \text { Design } 2 & \text { Design } 3 & \text { Design } 4 & \text { Design } 5\end{array}$
Fig. 14 Cost of refrigeration service with a $50-\mathrm{L}$ refrigerator under alternative assumptions about cost and efficiency improvement. Discount rate $8 \%$
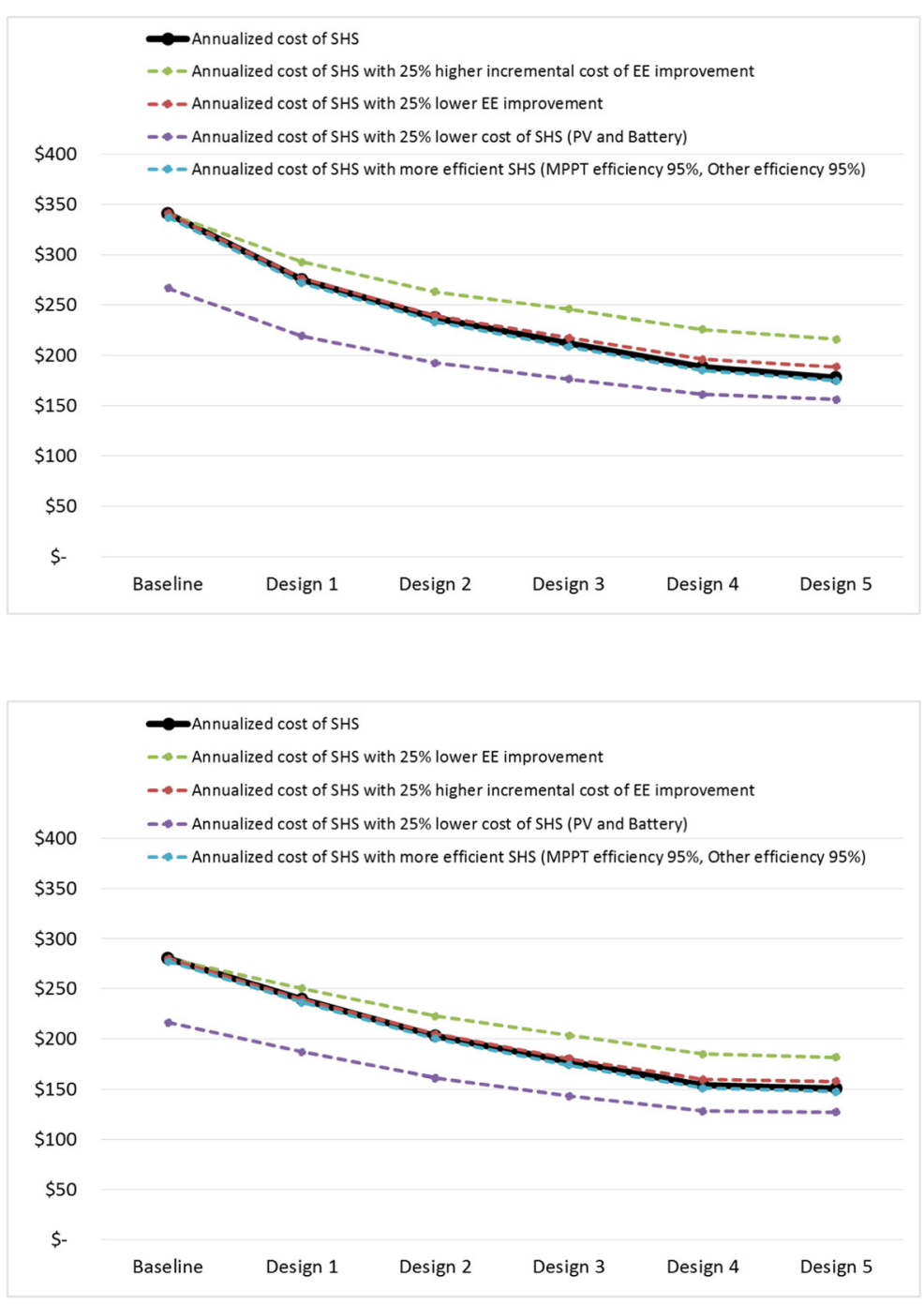
Fig. 15 Cost of refrigeration service with a $100-\mathrm{L}$ refrigerator under alternative assumptions about cost and efficiency improvement. Discount rate $8 \%$

Fig. 16 Cost of refrigeration service with a $50-\mathrm{L}$ refrigerator under alternative assumptions about cost and efficiency improvement. Discount rate $15 \%$
Fig. 17 Cost of refrigeration service with a $100-\mathrm{L}$ refrigerator under alternative assumptions about cost and efficiency improvement. Discount rate $15 \%$
Annualized cost of SHS

- Annualized cost of SHS with 25\% lower EE improvement

- Annualized cost of SHS with $25 \%$ higher incremental cost of EE improvement

- - Annualized cost of SHS with $25 \%$ lower cost of SHS (PV and Battery)

- - Annualized cost of SHS with more efficient SHS (MPPT efficiency 95\%, Other efficiency 95\%)

$\$ 300$

$\$ 250$

$\$ 200$

$\$ 150$

$\$ 100$

$\$ 50$

\$-

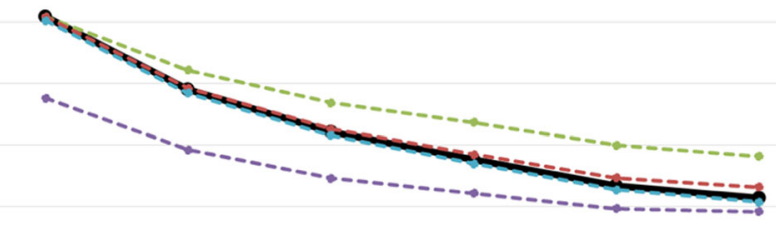

$\begin{array}{lllll}\text { Baseline Design } 1 & \text { Design } 2 & \text { Design } 3 & \text { Design } 4 & \text { Design } 5\end{array}$
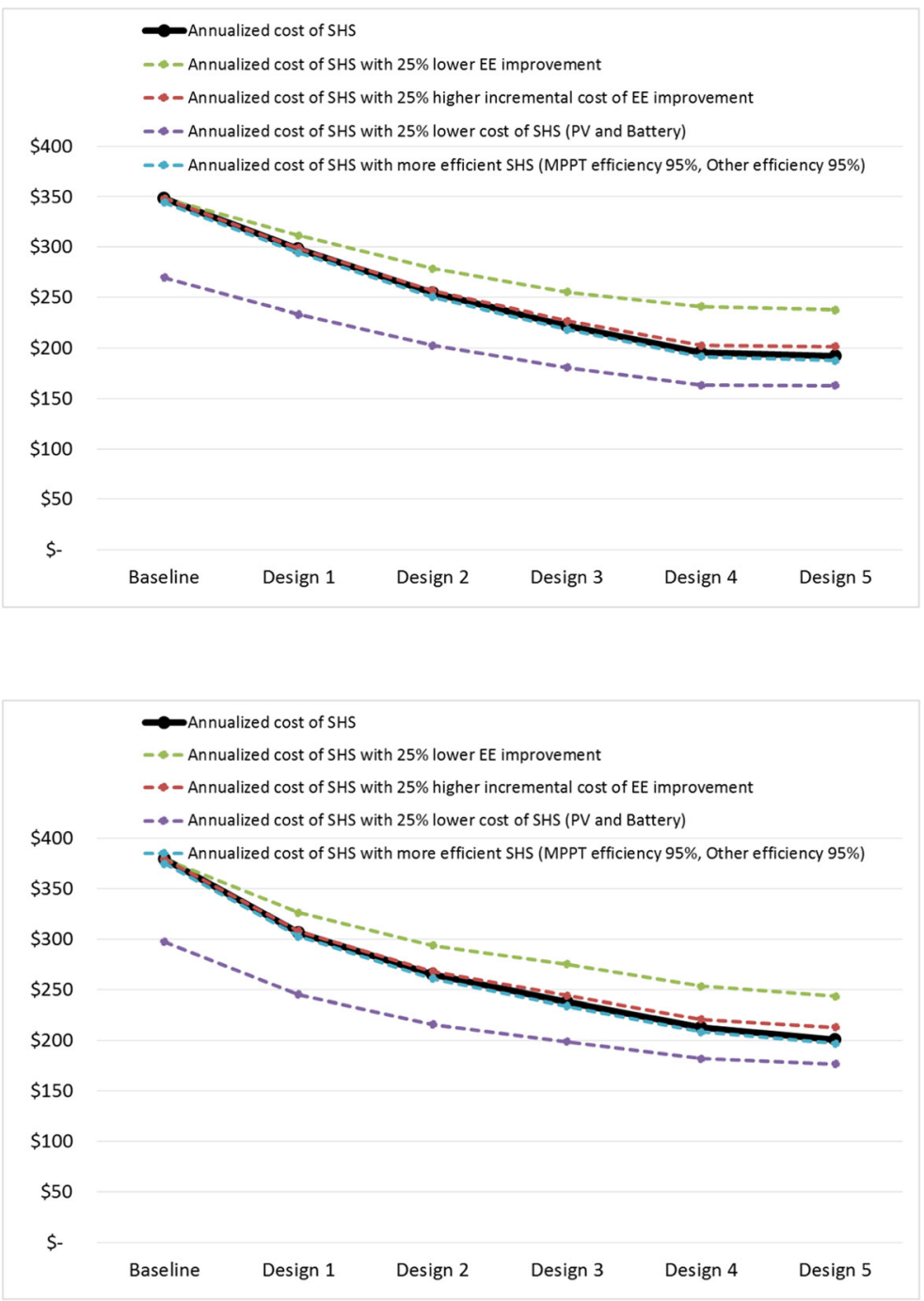


\section{Appendix 5 Estimated purchase price of solar home systems with refrigerators}

Figures 18 and 19 illustrate the results of estimated SHS prices in 2017 by scenario. The total cost of SHS with a 50-L super-efficient refrigerator is expected to decrease by $13 \%$ (for lead-acid battery) and $40 \%$ (for Li-ion battery) with $63 \%$ smaller PV and battery capacities required, compared with the same energy system with a standard refrigerator.
The total cost of SHS with a 100-L super-efficient refrigerator is expected to decrease by $11 \%$ (for lead-acid battery) and $42 \%$ (for Li-ion battery) with $70 \%$ smaller PV and battery capacities required, compared with the same energy system with a standard refrigerator. Although energyefficient refrigerators cost more than less efficient models, their adoption contributes to the decline in overall solar home system cost. Similar results would also apply over a range of system sizes, appliance types, and applications.
Fig. 18 Estimated purchase price in 2017 of solar home systems with a 50-L refrigerator under the baseline and the efficiency improvement scenario with design 5. Up-front cost is estimated retail price. SE super-efficient

Fig. 19 Estimated purchase price in 2017 of solar home systems with a $100-\mathrm{L}$ refrigerator under the baseline and the efficiency improvement scenario with design 5. Up-front cost is estimated retail price. SE super-efficient
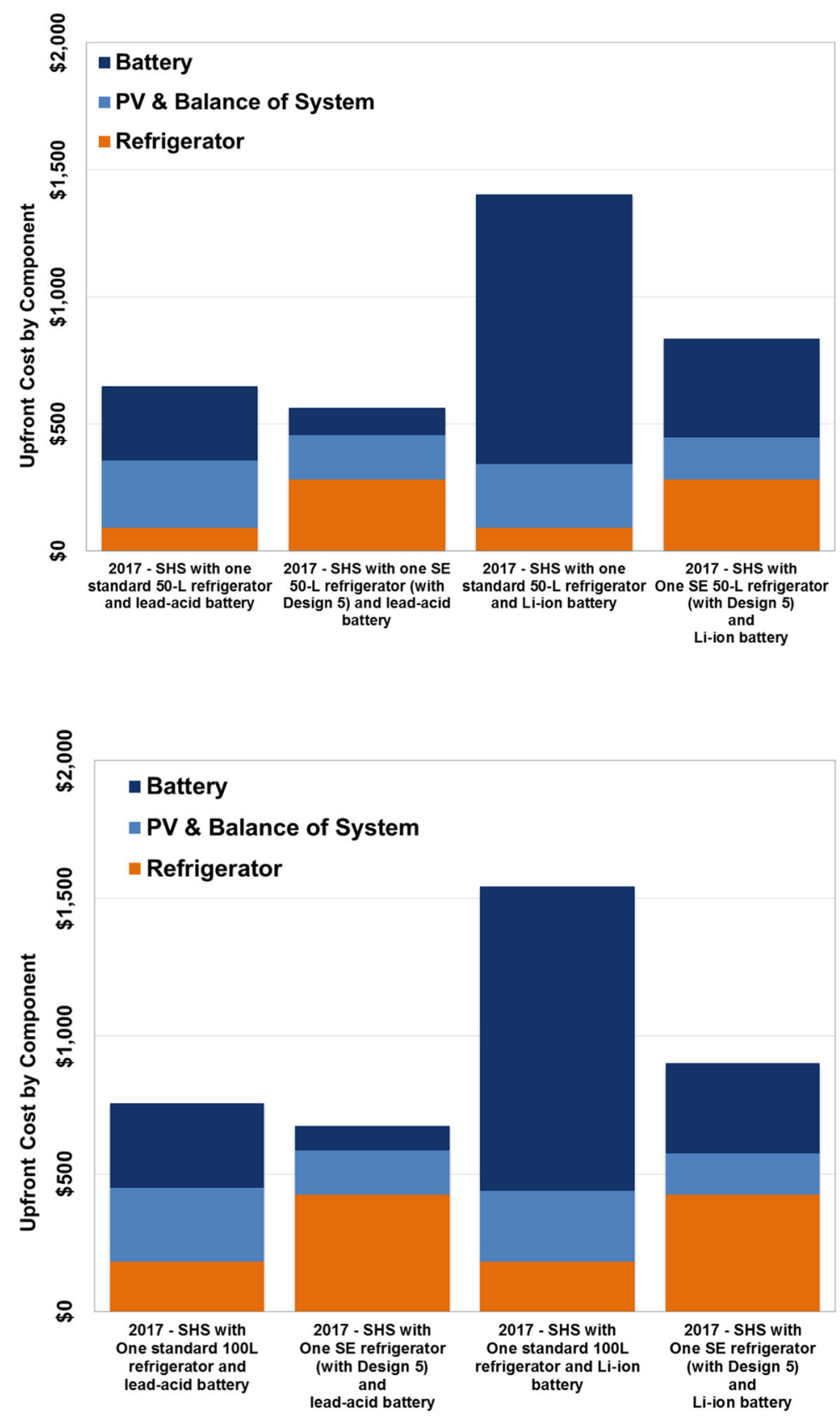
Open Access This article is distributed under the terms of the Creative Commons Attribution 4.0 International License (http:// creativecommons.org/licenses/by/4.0/), which permits unrestricted use, distribution, and reproduction in any medium, provided you give appropriate credit to the original author(s) and the source, provide a link to the Creative Commons license, and indicate if changes were made.

\section{References}

Africa-EU Renewable Energy Cooperation Programme (RECP). (2014). Mini-grid policy toolkit-policy and business frameworks for successful mini-grid rollouts. http://www.ren21.net/Portals/0 /documents/Resources/MGT/MinigridPolicyToolkit_Sep2014 EN.pdf. Accessed 13 Nov 2017.

Akhil, A., Huff, G., Currier, A., Kaun, B., Rastler, D., Chen, S., Cotter, A., Bradshaw, D., \& Gauntlett, W. (2013). DOE/EPRI 2013 Electricity storage handbook in collaboration with NRECA. Sandia: Sandia National Laboratories report SAND2013-5131.

Asia-Pacific Economic Cooperation (APEC) (2016). Differences/ synergies between energy efficiency test methods for refrigerators in APEC region and with the new IEC $62552-$ Laboratory Test Report. Energy Working Group. March.

Casillas, C. E., \& Kammen, D. M. (2010). The energy-povertyclimate nexus. Science, 330(6008), 1181-1182.

Desroches, L.-B., \& Garbesi, K. (2011). Max tech and beyondmaximizing appliance and equipment efficiency by design. Berkeley: Lawrence Berkeley National Laboratory report LBNL-4998E.

Franz, M., N. Peterschmidt, M. Rohrer, B. Kondev. 2014. Mini-grid policy toolkit - policy and business frameworks for successful mini-grid roll-outs. European Union Energy Initiative Partnership Dialogue Facility (EUEI PDF). http://www.ren21.net/Portals/0 /documents/Resources/MGT/MinigridPolicyToolkit Sep2014_EN.pdf. Accessed 13 Nov 2017.

Garbesi, K., Vossos, V., \& Shen, H. (2011). Catalog of DC appliances and power systems. Berkeley: Lawrence Berkeley National Laboratory report LBNL-5364E.

GIZ (2016). Photovoltaics for productive use applications: a catalogue of DC-appliances.

Global LEAP (2016). The state of the off-grid appliance market. $\mathrm{http} / / /$ static1.squarespace.com/static/56ba427f9f726695ab77 ec09/t/56d45d8c2b8dde6611d2803c/1457985229689 /Global+LEAP+\%2D\%2D+The+State+of+the+Global+OffGrid+Appliance+Market+\%28Feb+2016\%29+Print.pdf. Accessed 13 Nov 2017.

Global LEAP (2017). Test data of off-grid refrigerators and refrigerator-freezers.

Global Lighting and Energy Access Partnership (Global LEAP) (2015). Global LEAP off-grid appliance market survey. April. http://www.cleanenergyministerial.org/Portals/2 /pdfs/GlobalLEAPOff-GridApplianceSurvey-April2015.pdf. Accessed 13 Nov 2017.

GNESD (2014). Renewable energy-based rural electrification: the mini-grid experience from India. Prepared by The
Energy and Resources Institute (TERI) for the Global Network on Energy for Sustainable Development (GNESD).

Gretz, A. (2016). Lead acid, or lithium-ion home batteries? SWELL Energy. https://www.swellenergy.com/blog/2016 /06/17/lead-acid-vs-lithium-ion-batteries-which-is-better-forstoring-solar. Accessed 13 Nov 2017.

Infrastructure Development Company Limited (IDCOL) (2014). IDCOL solar home system. Presented by S. M. Monirul Islam. https://www.esmap.org/sites/esmap. org/files/ESMAP_SAR_EAP_Renewable_Energy_ Resource_Mapping_Islam.pdf. Accessed 13 Nov 2017.

International Energy Agency (IEA) (2015). Electricity access in $2013 \mathrm{http}: / / \mathrm{www}$.worldenergyoutlook. org/resources/energydevelopment/energyaccessdatabase/. Accessed 13 Nov 2017.

InvestmentMine (2016). 5-Year copper prices and price charts. $\mathrm{http}: / / \mathrm{www}$.infomine.com/investment/metal-prices/copper/5year/. Accessed 13 Nov 2017.

Majumder, S. (2015). The village that just got its first fridge. Calcutta: BBC News 28 January. http://www.bbc. com/news/magazine-30925252. Accessed 13 Nov 2017.

Mallampalli, S., Bohori, A. (2012). Design and development of three phase permanent magnet brushless DC (PM BLDC) motor for variable speed. International Compressor Engineering Conference at Purdue University, July 16-19.

McCarney, S., Robertson, J., Arnaud, J., Lorenson, K., \& Lloyd, J. (2013). Using solar-powered refrigeration for vaccine storage where other sources of reliable electricity are inadequate or costly. Vaccine, 31(51), 6050-6057.

McNeil, M. A., Ke, J., Can, Can, S. d. 1. R. d., Letschert, V. E., \& McMahon, J. E. (2011). Business case for energy efficiency in support of climate change mitigation, economic and societal benefits in India. November. Berkeley: Lawrence Berkeley National Laboratory report LBNL-5344E. https://ies.lb1. gov/sites/all/files/lbnl-5344e 1.pdf. Accessed 13 Nov 2017.

PATH and World Health Organization (WHO) (2013). Directdrive solar vaccine refrigerators - a new choice for vaccine storage. https://www.path.org/publications/files/TS_opt ebs_dd_solar_fridge.pdf. Accessed 13 Nov 2017.

Phadke, A., Jacobson, A., Park, W., Lee, G., Alstone, P., \& Khare, A. (2015). Power a home with just 25 watts of solar PV. Berkeley: Lawrence Berkeley National Laboratory report LBNL-175726. http://eetd.lbl.gov/publications/powering-ahome-with-just-25watts-of-. Accessed 13 Nov 2017.

Schnitzer, D., Shinde Lounsbury, D., Carvallo, J. P., Deshmukh, R., Apt, J., Kammen, D. (2014). Microgrids for rural electrification: a critical review of best practices based on seven case studies. United Nations Foundation. https://rael. berkeley.edu/wp-content/uploads/2015/04 /MicrogridsReportEDS.pdf. Accessed 13 Nov 2017.

Serdarevic, E. (2012). Extend battery life by implementing soft start. 28 March. http://powerelectronics.com/powerelectronics-systems/extend-battery-life-implementing-softstart. Accessed 13 Nov 2017.

Shah, N., Sathaye, N., \& Phadke, A. (2014a). Efficiency improvement opportunities for ceiling fans. Energy Efficiency, 8, 3750. https://doi.org/10.1007/s12053-014-9274-6.

Shah, N., W. Y. Park, N. Bojda, M. McNeil, P. Waide. 2014b. Superefficient refrigerators: opportunities and challenges for efficiency improvement globally. 2014 ACEEE Summer Study on Energy Efficiency in Buildings. http://eetd.lbl. 
gov/publications/superefficient-refrigerators-opportun. Accessed 13 Nov 2017.

SunDanzer (n.d.). DC refrigerators and freezers. http://www. sundanzer.com/. Accessed 13 Nov 2017.

Terrell, W. (2006). Energy requirements of refrigerators due to door opening conditions. International refrigeration and air conditioning conference. Paper 836. http://docs.lib.purdue. edu/iracc/836. Accessed 13 Nov 2017.

Topten.eu. (2015). Refrigerators freestanding - 1 door with freezer. Updated June 30, 2015. http://www.topten. eu/english/household/refrigerator_freestanding/1-door-withfreezer.html.

U.S. DOE (2013). Technical support document for energy conservation standards for commercial refrigerators, refrigeratorfreezers, and freezers. https://www1.eere.energy. gov/buildings/appliance_standards/pdfs/cre2_nopr_ tsd_2013_08_28.pdf. Accessed 13 Nov 2017.

U.S. EPA (2016). List of ENERGY STAR-qualified refrigerators.

United States Agency for International Development (U.S.AID) (2014). Assessment of the role of energy storage technologies for renewable energy deployment in India. http://pdf.usaid. gov/pdf_docs/PA00JRNH.pdf. Accessed 13 Nov 2017.

United States Department of Energy (U.S. DOE) (2011). Technical support document for energy conservation standards for residential refrigerators, refrigerator-freezers, and freezers. https://www1.eere.energy.gov/buildings/appliance standards/pdfs/refrig_finalrule_tsd.pdf. Accessed 13 Nov 2017.
United States Environmental Protection Agency (U.S. EPA) (2014). ENERGY STAR market \& industry scoping report miscellaneous residential refrigeration products. August. https://www. energystar.gov/sites/default/files/asset/document/ENERGY STAR_Scoping_Misc_Residential_Refrigerators.pdf. Accessed 13 Nov 2017.

VHK and ARMINES (2016). Commission Regulation (EC) No. $643 / 2009$ with regard to ecodesign requirements for household refrigeration appliances and Commission Delegated Regulation (EU) No. 1060/2010 with regard to energy labelling of household refrigeration appliances - final report. Preparatory/Review Study. March. https://www.eupnetwork.de/fileadmin/user upload/2016/Household

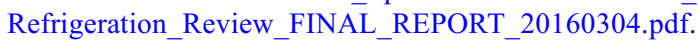
Accessed 13 Nov 2017.

World Health Organization (WHO) (2016). Performance quality safety (PQS) devices catalogue - E003 refrigerators and freezers. WHO/IVB/11.08. 28 June 2016.

Zhuang, J., Liang, Z., Lin, T., Guzman, F. (2007). Theory and practice in the choice of social discount rate for cost-benefit analysis: a survey. Economics and research department (ERD) working paper series No. 94. Asian Development Bank. https://www.adb.org/sites/default/files/publication/28360 /wp094.pdf. Accessed 13 Nov 2017.

Publisher's note Springer Nature remains neutral with regard to jurisdictional claims in published maps and institutional affiliations. 